Western University

Scholarship@Western

$11-2018$

Fast and slow-twitching muscles are differentially affected by reduced cholinergic transmission in mice deficient for VAChT: A mouse model for congenital myasthenia

Matheus P.S. Magalhaes-Gomes

Marco A.M. Prado

Follow this and additional works at: https://ir.lib.uwo.ca/anatomypub

Part of the Anatomy Commons, and the Cell and Developmental Biology Commons 


\title{
Fast and slow-twitching muscles are differentially affected by reduced cholinergic transmission in mice deficient for VAChT: A mouse model for congenital myasthenia
}

\author{
Matheus P.S. Magalhães-Gomes ${ }^{\mathrm{a}}$, Daisy Motta-Santos ${ }^{\mathrm{b}, \mathrm{h}}$, Luana P.L. Schetino ${ }^{\mathrm{a}, 1}$, \\ Jéssica N. Andrade ${ }^{\mathrm{a}}$, Cristiane P. Bastos ${ }^{\mathrm{b}}$, Diogo A.S. Guimarães ${ }^{\mathrm{c}}$, Sydney K. Vaughan ${ }^{\mathrm{e}, \mathrm{f}}$, \\ Patrícia M. Martinelli ${ }^{\mathrm{a}}$, Silvia Guatimosim ${ }^{\mathrm{b}}$, Grace S. Pereira ${ }^{\mathrm{b}}$, Candido C. Coimbra ${ }^{\mathrm{b}}$, \\ Vânia F. Prado ${ }^{\mathrm{d}}$, Marco A.M. Prado ${ }^{\mathrm{d}}$, Gregorio Valdez ${ }^{\mathrm{e}, \mathrm{g}}$, Cristina Guatimosim ${ }^{\mathrm{a}, *}$ \\ ${ }^{a}$ Departamento de Morfologia, ICB, Universidade Federal de Minas Gerais, Belo Horizonte, MG, Brazil \\ ${ }^{\mathrm{b}}$ Departamento de Fisiologia e Biofísica, ICB, Universidade Federal de Minas Gerais, Belo Horizonte, MG, Brazil \\ ${ }^{\mathrm{c}}$ IEP-Santa Casa, Belo Horizonte, MG, Brazil \\ ${ }^{\mathrm{d}}$ Robarts Research Institute and Department of Physiology and Pharmacology and Anatomy \& Cell Biology, University of Western Ontario, London, ON, Canada \\ e Virginia Tech Carilion Research Institute, Roanoke, VA, USA \\ ${ }^{\mathrm{f}}$ Graduate Program in Translational Biology, Medicine, and Health, Virginia Tech, Blacksburg, VA, USA \\ ${ }^{g}$ Department of Biological Sciences, Virginia Tech, Blacksburg, VA, USA \\ ${ }^{\mathrm{h}}$ Departamento de Esportes, EEFFTO, Universidade Federal de Minas Gerais, Belo Horizonte, MG, Brazil
}

\section{A R T I C L E I N F O}

\section{Keywords:}

Congenital myasthenic syndromes

Acetylcholine

Vesicular acetylcholine transporter skeletal muscle

Cholinergic transmission

Motor function

\begin{abstract}
A B S T R A C T
Congenital myasthenic syndromes (CMS) result from reduced cholinergic transmission at neuromuscular junctions (NMJs). While the etiology of CMS varies, the disease is characterized by muscle weakness. To date, it remains unknown if CMS causes long-term and irreversible changes to skeletal muscles. In this study, we examined skeletal muscles in a mouse line with reduced expression of Vesicular Acetylcholine Transporter (VAChT, mouse line herein called VAChT- $\mathrm{KD}^{\mathrm{HOM}}$ ). We examined this mouse line for several reasons. First, VAChT plays a central function in loading acetylcholine (ACh) into synaptic vesicles and releasing it at NMJs, in addition to other cholinergic nerve endings. Second, loss of function mutations in VAChT causes myasthenia in humans. Importantly, VAChT-KD ${ }^{\mathrm{HOM}}$ present with reduced $\mathrm{ACh}$ and muscle weakness, resembling CMS. We evaluated the morphology, fiber type (myosin heavy chain isoforms), and expression of muscle-related genes in the extensor digitorum longus (EDL) and soleus muscles. This analysis revealed that while muscle fibers atrophy in the EDL, they hypertrophy in the soleus muscle of VAChT-KD ${ }^{\mathrm{HOM}}$ mice. Along with these cellular changes, skeletal muscles exhibit altered levels of markers for myogenesis (Pax-7, Myogenin, and MyoD), oxidative metabolism (PGC1- $\alpha$ and MTND1), and protein degradation (Atrogin1 and MuRF1) in VAChT-KD ${ }^{\text {HOM }}$ mice. Importantly, we demonstrate that deleterious changes in skeletal muscles and motor deficits can be partially reversed following the administration of the cholinesterase inhibitor, pyridostigmine in VAChT-KD ${ }^{\mathrm{HOM}}$ mice. These findings reveal that fast and slow type muscles differentially respond to cholinergic deficits. Additionally, this study shows that the adverse effects of cholinergic transmission, as in the case of CMS, on fast and slow type skeletal muscles are reversible.
\end{abstract}

\section{Introduction}

Congenital Myasthenic Syndromes (CMS) are a group of genetic disorders that impair neuromuscular transmission, resulting in muscle weakness (Aran et al., 2017; O'Neill, 2006). CMS are generally caused by mutations in presynaptic and postsynaptic genes with crucial roles in cholinergic transmission at the neuromuscular junction (NMJ) (Ohno et al., 2017). One of the most relevant proteins for cholinergic

\footnotetext{
* Corresponding author. LaBNeuro, Bloco H2, sala 210, Departamento de Morfologia, ICB, Universidade Federal de Minas Gerais. Avenida Antonio Carlos, 6627, Pampulha, Belo Horizonte, MG, 31.270-901, Brazil.

E-mail address: cguati@icb.ufmg.br (C. Guatimosim).

${ }^{1}$ Current address: Faculdade de Medicina, Universidade Federal dos Vales do Jequitinhonha e Mucuri, Campus JK, Diamantina, MG, Brasil.
} 


$\begin{array}{ll}\text { Abbreviations } \\ \text { ACh } & \text { acetylcholine } \\ \text { ALS } & \text { amyotrophic lateral sclerosis } \\ \text { ChAT } & \text { choline acetyltransferase } \\ \text { CMS } & \text { congenital myasthenic syndrome } \\ \text { CSA } & \text { cross sectional area } \\ \text { EDL } & \text { extensor digitorum longus muscle } \\ \text { MIT } & \text { maximal incremental test } \\ \text { MTND1 } & \text { mitochondrial DNA encoding complex 1 } \\ \text { MuRF1 } & \text { muscle RING-finger protein-1 } \\ \text { MyHC } & \text { myosin heavy chain } \\ \text { MyoD } & \text { myogenic differentiation 1 }\end{array}$

transmission is Vesicular Acetylcholine Transporter (VAChT), encoded by the SLC18A3 gene. Mutations in this gene were recently identified in patients presenting with differing degrees of myasthenia (OMIN number: \# 617239) (Aran et al., 2017; O'Grady et al., 2016; Schwartz et al., 2018). VAChT functions to move acetylcholine (ACh) into synaptic vesicles (Kljakic et al., 2017; Parsons, 2000; Prado et al., 2013) following its synthesis by choline acetyltransferase (ChAT). Under steady-state conditions, VAChT transports sufficient ACh into synaptic vesicles to activate acetylcholine receptors (AChRs) on the muscle fiber membrane to promote muscle contraction (Katz and Miledi, 1964; Langley, 1907). However, mutations in VAChT (de Castro et al., 2009; Prado et al., 2006) reduce the amount of ACh loaded into synaptic vesicles, thus impairing AChR activation and muscle contraction.

In addition to causing CMS, loss of ACh affects the formation and development of muscle fibers and their NMJs (Darabid et al., 2014; Gautam et al., 1999; Miner et al., 1998). Highlighting this point, deletion of ChAT or VAChT in mice affects the morphology and function of nascent NMJs and muscle fibers, and invariably results in early postnatal death due to lack of cholinergic transmission (Brandon et al., 2003; de Castro et al., 2009; Misgeld et al., 2002). To further assess the contribution of ACh to NMJ and muscle development, transgenic mice with reduced expression of VAChT were generated and examined in previous published studies. This involved introducing a selection marker cassette within the 5'untranslated region of the VAChT gene to interfere with VAChT expression (Prado et al., 2006) using homologous recombination. Transgenic mice with both VAChT gene locus modified are referred to as VAChT- $\mathrm{KD}^{\mathrm{HOM}}$. These mice present with $65 \%$ reduction in VAChT levels, shown using qPCR and western blot analysis, yet survive and reach adulthood despite having a pronounced deficit in neuromuscular transmission and function (Lima et al., 2010; Prado et al., 2006; Rodrigues et al., 2013). VAChT-KD ${ }^{\text {HOM }}$ also exhibit cardiac dysfunction (Lara et al., 2010), increased inflammatory responses (Leite et al., 2016), and cognitive impairment (Prado et al., 2006). Thus, the phenotypes described in VAChT deficient mice closely resemble phenotypes found in human patients with VAChT mutations, suggesting a high degree of functional conservation and further indicating that low levels of ACh causes CMS in VAChT transgenic mice (Aran et al., 2017; O'Grady et al., 2016).

Although pre-synaptic alterations in adult VAChT-KD ${ }^{\mathrm{HOM}}$ mice have been reported (Lima et al., 2010; Prado et al., 2006; Rodrigues et al., 2013), it is still unknown whether long-term changes in cholinergic activity due to VAChT deficiency causes long-term changes in the structure and function of skeletal muscles. In most mammals, adult skeletal muscles are populated by four types of muscle fibers, which can be identified based on the expression of Myosin Heavy Chain (MyHC) isoforms. The four types of MyHC are: type 1 or slow-oxidative fibers; $2 \mathrm{~A}$ or fast oxidative-glycolytic; and $2 \mathrm{X}$ and $2 \mathrm{~B}$, which are fast-glycolytic fibers. The unique metabolic and contractile properties of these muscle fibers underlie the different functional outputs of skeletal muscles (Bloemberg and Quadrilatero, 2012; Brooke and Kaiser, 1970;

\author{
AChRs nicotinic receptors \\ NMJ neuromuscular junctions \\ Pax-7 paired box protein 7 \\ PGC1- $\alpha$ peroxisome proliferator-activated receptor gamma coac- \\ tivator 1-alpha \\ PYR pyridostigmine \\ SLC18A3 solute carrier family 18 member A3 \\ SMA spinal muscular atrophy \\ SR sarcoplasmic reticulum \\ TEM transmission electron microscopy \\ TTX tetrodotoxin \\ VAChT KD ${ }^{\mathrm{HOM}}$ VAChT knockdown Homozygous mice \\ VAChT vesicular acetylcholine transporter
}

Chakkalakal et al., 2010; Schiaffino et al., 1989; Schiaffino and Reggiani, 2011). These muscle fibers also show different responses to various diseases and aging. Despite this knowledge and obvious effects of CMS on the function of NMJs and whole skeletal muscles, little is known about the specific and long-term changes that suboptimal cholinergic transmission causes on muscle fibers. In this study, we examined skeletal muscles with varying functional demands and different muscle fiber composition in VAChT-KD ${ }^{\mathrm{HOM}}$ mice. We also assessed if pathogenic features resembling CMS are reversible in adult skeletal muscles of VAChT-KD ${ }^{\mathrm{HOM}}$ mice.

\section{Materials and methods}

\subsection{Experimental design}

The generation and genotyping of VAChT- $\mathrm{KD}^{\mathrm{HOM}}$ transgenic mice was previously described (Prado et al., 2006). VAChT-KD ${ }^{\text {HOM }}$ mice have a 65\% reduction in VAChT expression. All animals were genotyped 10 days after birth. VAChT-KD ${ }^{\mathrm{HOM}}$ mice were obtained by intercrossing heterozygous animals. Control mice were wild type (WT) age and sexmatched littermates. We only examined male adult (3-6 months-old) mice in this study. Animals were housed in an animal care facility in Department of Physiology and Biophysics, Universidade Federal de Minas Gerais (UFMG). Animals were grouped with three to five animals into mini-isolator cages (length: $48,3 \mathrm{~cm}$; width: $33,7 \mathrm{~cm}$; height: $21,4 \mathrm{~cm}$ - Alesco $\left.{ }^{\circ}\right)$ in a temperature-controlled room $\left(\sim 24^{\circ} \mathrm{C}\right)$ with a 12:12 light-dark cycles, with food (Nuvilab CR-1) and water provided ad libitum. Mice weight was approximately $28.6 \pm 2.8 \mathrm{~g}$ for WT and $24.2 \pm 2.7 \mathrm{~g}$ for VAChT-KD ${ }^{\mathrm{HOM}}$ mice (see Table 3 ). The experimental procedures were carried out in accordance with the protocol approved by the UFMG ethics committee (CEUA, protocol 40/2009) and in accordance with NIH and ARRIVE guidelines for the Care and Use of Animals in Research and Teaching. All efforts were made to minimize animal suffering and to reduce the number of animals used.

All animals used in this study were appropriately identified by numbers according to their genotype (WT or VAChT-KD ${ }^{\mathrm{HOM}}$ ). Using the genotyping table, animals were randomly divided into the following groups: Group one, untreated: WT and VAChT-KD ${ }^{\mathrm{HOM}}$; Group two treated with Pyridostigmine (PYR): WT, WT PYR, VAChT-KD ${ }^{\mathrm{HOM}}$ and VAChT-KD ${ }^{\mathrm{HOM}}$ PYR. Animals were randomly treated and evaluated.

The animals assigned to group one were deeply anesthetized by inhalation of isoflurane in a glass chamber or with ketamine/xylazine $(0.1 \mathrm{~mL} / 20 \mathrm{~g})$. All procedures were performed in accordance to the CEUA/UFMG protocol. All surgical procedures are described in the appropriated sections. The experimental procedures were mostly performed in the afternoon, and by the end of each surgical procedure animals were euthanized using a super-dosage of anesthetics. The experiments were conducted at the Department of Morphology and Physiology on Federal University of Minas Gerais. The exact numbers for all experiments are provided in the figure legends and results 
Table 1

Quantitative analyses of the EDL muscle from WT and VAChT-KD ${ }^{\mathrm{HOM}}$ mice.

\begin{tabular}{|c|c|c|c|}
\hline EDL & WT & VAChT-KD ${ }^{\text {HOм }}$ & $\begin{array}{l}\text { Statistics } \\
(\mathrm{p}<0.05)\end{array}$ \\
\hline $\begin{array}{c}\text { Whole muscle } \\
\text { area } \\
\left(\mathrm{mm}^{2}\right)\end{array}$ & $1.8 \pm 0.06$ & $1.4 \pm 0.06^{*}$ & $p=0.0016$ \\
\hline $\begin{array}{c}\text { Total number } \\
\text { of fibers }\end{array}$ & $979 \pm 74.5$ & $778 \pm 22.6^{*}$ & $\mathrm{p}=0.0140$ \\
\hline $\begin{array}{l}\text { Mean fibers } \\
\qquad \text { CSA }\left(\mu \mathrm{m}^{2}\right)\end{array}$ & $1735 \pm 91.2$ & $1429 \pm 55.6^{*}$ & $\mathrm{p}=0.016$ \\
\hline $\begin{array}{c}\text { Type 2A CSA } \\
\left(\mu \mathrm{m}^{2}\right)\end{array}$ & $640.5 \pm 35.1$ & $540.3 \pm 42.7$ & NS \\
\hline $\begin{array}{c}\text { Type } 2 \mathrm{X} \text { CSA } \\
\left(\mu \mathrm{m}^{2}\right)\end{array}$ & $892.4 \pm 50.9$ & $700.9 \pm 47.2^{*}$ & $\mathrm{p}=0.02$ \\
\hline $\begin{array}{c}\text { Type 2B CSA } \\
\left(\mu \mathrm{m}^{2}\right)\end{array}$ & $2344 \pm 67.7$ & $1758 \pm 58.8^{*}$ & $\mathrm{p}=0.0002$ \\
\hline$\%$ of type $2 \mathrm{~A}$ & $5.6 \pm 0.7$ & $8.4 \pm 1.03$ & NS \\
\hline$\%$ of Type $2 \mathrm{X}$ & $16.3 \pm 1.4$ & $25.9 \pm 1.1^{*}$ & $\mathrm{p}=0.0008$ \\
\hline$\%$ of Type $2 B$ & $74 \pm 2.6$ & $64.6 \pm 2.06^{*}$ & $\mathrm{p}=0.04$ \\
\hline $\begin{array}{l}\text { Molecular } \\
\text { markers } \\
\left(2^{-\Delta \Delta \mathrm{CT}}\right)\end{array}$ & WT & VAChT-KD ${ }^{\text {HOM }}$ & $\begin{array}{l}\text { Statistics } \\
(p<0.05)\end{array}$ \\
\hline Atrogin-1 & $0.0089 \pm 0.0013$ & $0.004 \pm 0.0009^{*}$ & $\mathrm{p}=0.02$ \\
\hline MuRF-1 & $0.0128 \pm 0.002$ & $0.0114 \pm 0.0021$ & NS \\
\hline Pax-7 & $0.0003 \pm 0.00002$ & $0.0003 \pm 0.00003$ & NS \\
\hline MyoD & $0.0012 \pm 0.0002$ & $0.0002 \pm 0.00003^{*}$ & $\mathrm{p}=0.0005$ \\
\hline Myogenin & $0.00036 \pm 0.00002$ & $0.00019 \pm 0.00001 *$ & $\mathrm{p}=0.0003$ \\
\hline PGC1- $\alpha$ & $0.0026 \pm 0.0001$ & $0.0019 \pm 0.0001$ & NS $(p=0.06)$ \\
\hline MTND1 & $4.88 \pm 0.75$ & $3.14 \pm 0.36^{*}$ & $\mathrm{p}=0.047$ \\
\hline
\end{tabular}

Statistical analysis was deployed to compare morphological differences between 5 WT and 7 VAChT-KD ${ }^{\mathrm{HOM}}$ mice. The average whole muscle area and variability was compared between genotypes. For individual muscle fiber crosssectional area (CSA) analysis, we evaluated a total of 2767 fibers per genotype: 316 for type 2A, 544 for type 2X, and 1907 for type 2B. Molecular analysis was performed in $3 \mathrm{WT}$ and $6 \mathrm{VAChT}-\mathrm{KD}^{\mathrm{HOM}}$ mice. Values represent Mean \pm SEM. Unpaired Student's t-test was applied after the data was analyzed using Kolmogorov-Smirnov normality test. * Statistically different from WT mice. \# Mann-Whitney test for non-Gaussian data set. NS: Not Significant.

section. The experimental groups remained constant from the beginning to the end of the study.

\subsection{Morphological and morphometrical analyses}

Mice were anesthetized with isoflurane, followed by cervical dislocation. The gastrocnemius, extensor digitorum longus (EDL) and soleus muscles were surgically excised, fixed in $4 \%$ glutaraldehyde for $24 \mathrm{~h}$, dehydrated in an ascending volumes of alcohol (70\%, 80\%, 90\%, $95 \% 2 \mathrm{X}$ ), embedded in glycol methacrylate resin (Leica), and cut in a microtome (Reichert Jung). The mid-belly regions of muscles were cut into $3-5 \mu \mathrm{m}$ thick sections. Muscle sections were stained with toluidine blue (EMS) for cross-sectional area (CSA) analysis of individual myofibers. Images were acquired using a microscope (Zeiss Axiolab A1) coupled to a CCD camera, visualized in a computer and analyzed using the Axiovision (Zeiss) or Image $\mathrm{J}(\mathrm{NIH})$ where a polygon selection tool was used to manually draw a perimeter around muscle fibers to determine the CSA of individual myofibers. The average CSA for gastrocnemius muscle fibers were calculated from at least 500 individual muscle fibers per animal per genotype.

\subsection{Myosin heavy chain isoforms staining}

Myosin heavy chain isoforms were identified according to the protocol described by Valdez et al. (2012). Mice were sacrificed, and then EDL, gastrocnemius and soleus muscles were collected, immersed in OCT (Easy Path), oriented in freezing molds, and covered with freezing medium. The EDL and Soleus were put in the same mold and freshly
Table 2

Quantitative analyses of the soleus muscle from WT and VAChT-KD ${ }^{\mathrm{HOM}}$ mice.

\begin{tabular}{|c|c|c|c|}
\hline Soleus & WT & VAChT-KD & $\begin{array}{l}\text { Statistics } \\
(\mathrm{p}<0.05)\end{array}$ \\
\hline $\begin{array}{l}\text { Whole muscle } \\
\quad \text { area }\left(\mathrm{mm}^{2}\right)\end{array}$ & $1.45 \pm 0.12$ & $1.5 \pm 0.09$ & NS \\
\hline $\begin{array}{l}\text { Total number of } \\
\text { fibers }\end{array}$ & $856.2 \pm 22.8$ & $730.3 \pm 28.19 *$ & $\mathrm{p}=0.009$ \\
\hline $\begin{array}{l}\text { Mean fibers } \\
\quad \operatorname{CSA}\left(\mu \mathrm{m}^{2}\right)\end{array}$ & $1525 \pm 45.4$ & $1777 \pm 51.1^{*}$ & $\mathrm{p}=0.005$ \\
\hline $\begin{array}{c}\text { Type } 1 \text { CSA } \\
\left(\mu \mathrm{m}^{2}\right)\end{array}$ & $1691 \pm 75.6$ & $1960 \pm 92.3^{*}$ & $\mathrm{p}=0.04$ \\
\hline $\begin{array}{c}\text { Type 2A CSA } \\
\left(\mu \mathrm{m}^{2}\right)\end{array}$ & $1349 \pm 11.6$ & $1745 \pm 54.4^{*}$ & $\mathrm{P}<0.0001$ \\
\hline $\begin{array}{c}\text { Type 2X CSA } \\
\left(\mu \mathrm{m}^{2}\right)\end{array}$ & $1652 \pm 109.1$ & $1727 \pm 55.7$ & NS \\
\hline$\%$ of type 1 & $34.8 \pm 2.7$ & $43.8 \pm 1.03^{*}$ & $\mathrm{p}=0.007$ \\
\hline$\%$ of Type $2 \mathrm{~A}$ & $54.1 \pm 2.4$ & $46.5 \pm 1.8^{*}$ & $\mathrm{p}=0.03$ \\
\hline$\%$ of Type $2 \mathrm{X}$ & $11.1 \pm 2.4$ & $9.7 \pm 2.01$ & NS \\
\hline $\begin{array}{l}\text { Molecular } \\
\text { markers } \\
\left(2^{-\Delta \Delta \mathrm{CT}}\right)\end{array}$ & WT & VAChT-KD ${ }^{\text {HOM }}$ & $\begin{array}{l}\text { Statistics } \\
(\mathrm{p}<0.05)\end{array}$ \\
\hline Atrogin-1 & $0.0055 \pm 0.0009$ & $0.0094 \pm 0.0009^{*}$ & $\mathrm{p}=0.02$ \\
\hline MuRF-1 & $0.0122 \pm 0.0015$ & $0.0173 \pm 0.001 *$ & $\mathrm{p}=0.02$ \\
\hline Pax-7 & $0.0005 \pm 0.00008$ & $0.00146 \pm 0.0001^{*}$ & $\mathrm{p}=0.0008$ \\
\hline MyoD & $0.0002 \pm 0.00002$ & $0.0004 \pm 0.00002^{*}$ & $\mathrm{p}=0.001$ \\
\hline Myogenin & $0.0008 \pm 0.0001$ & $0.001 \pm 0.0001$ & $\mathrm{NS}^{\#}$ \\
\hline PGC1- $\alpha$ & $0.0038 \pm 0.0003$ & $0.0081 \pm 0.001 *$ & $\mathrm{p}=0.004^{\#}$ \\
\hline MTND1 & $8.39 \pm 0.76$ & $13.04 \pm 0.89^{*}$ & $\mathrm{p}=0.003$ \\
\hline
\end{tabular}

Statistical analysis was deployed to compare morphological differences between 6 WT and 7 VAChT-KD ${ }^{\text {HOM }}$ mice. The average whole muscle area and variability was compared between genotypes. For individual muscle fiber crosssectional area (CSA) analysis, we evaluated a total of 2835 muscle fibers per genotype: 1104 for type 1, 1186 for type 2A, and 397 for type 2X. Values represent Mean \pm SEM. Unpaired Student's t-test was applied after the data was analyzed by the Kolmogorov-Smirnov normality test. Molecular analysis was performed in $6 \mathrm{WT}$ and 6 VAChT-KD ${ }^{\mathrm{HOM}}$ mice. * Statistically different from WT mice. \# Mann-Whitney test for non-Gaussian data set. NS: Not Significant.

Table 3

Results of the maximal incremental test.

\begin{tabular}{llll}
\hline MIT TEST & WT & VAChT-KD $^{\text {HOM }}$ & Statistics \\
\hline Body weight (g) & $28.6 \pm 2.7$ & $24.25 \pm 2.6^{*}$ & $\mathrm{p}=0.03$ \\
Distance (m) & $417.3 \pm 132.6$ & $105.4 \pm 37.6^{*}$ & $\mathrm{p}=0.0004$ \\
Vmax (cm/s) & $31.2 \pm 4.02$ & $15.5 \pm 2.2^{*}$ & $\mathrm{p}<0.0001$ \\
Duration (min) & $26.8 \pm 4.4$ & $10.6 \pm 2.4^{*}$ & $\mathrm{p}<0.0001$ \\
$\mathrm{VO}_{2}$ Basal (ml.Kg-1.min-1) & $15.1 \pm 6.1$ & $13.4 \pm 4.3$ & $\mathrm{NS}$ \\
$\mathrm{VO}_{2}$ Max (ml.Kg-1.min-1) & $29.9 \pm 5.4$ & $25.8 \pm 4.2$ & $\mathrm{NS}$ \\
Work (J) & $21.1 \pm 7.5$ & $3.3 \pm 0.7^{*}$ & $\mathrm{p}=0.0003$
\end{tabular}

Statistical analysis was deployed to compare differences between 5 WT and 6 VAChT-KD ${ }^{\text {HOM }}$ mice. The average whole muscle area and variability was compared between genotypes. Values represent Mean \pm SEM. *Statistically different from WT mice based on Unpaired Student's t-test. NS: Not Significant.

frozen in isopentane (Sigma-Aldrich), cooled in liquid nitrogen, and stored at $-80^{\circ} \mathrm{C}$. The mid-belly region of muscles was cut on a cryostat (Leica CM3050S), and cross sections $(10 \mu \mathrm{m})$ were collected on gelatincoated slides. Muscle sections were blocked $30 \mathrm{~min}$ at room temperature (RT) with $3 \%$ BSA (Sigma-Aldrich), $5 \%$ goat serum (Sigma-Aldrich), and $0.1 \%$ Triton X-100 (Sigma-Aldrich) diluted in PBS $1 \mathrm{x}$. Muscle sections were then incubated overnight $(\mathrm{ON})$ at $4{ }^{\circ} \mathrm{C}$ with the following primary antibodies (diluted in $3 \%$ BSA, $5 \%$ goat serum), all raised in mice: type 1 (Leica Microsystems Cat\# NCL-MHCs Lot\# RRID:AB_563898; 1:250); type 2A (DSHB Cat\# SC-71 Lot\# RRID:AB_ 2147165; 1:100), type 2X (DSHB Cat\# BF-35 Lot\# RRID:AB_2274680, which recognizes all types of muscles fibers except for the $2 X ; 1: 100$ ), and type 2B (DSHB Cat\# BF-F3 Lot\# RRID:AB_2266724; 1:100). SC-71, 
BF-35 and BF-F3 antibodies were deposited to the DSHB by Stefano Schiaffino. Slides were washed three times with PBS $1 \mathrm{x}$ and incubated for $1 \mathrm{~h}$ at room temperature with secondary antibodies: Alexa 488 goat anti-mouse IgG1 (Thermo Fisher Scientific Cat\# A-21121 Lot\# RRID:AB_2535764. Recognizes the type 1, 2A and 2X antibodies) and Alexa 488 goat anti-mouse IgM (Thermo Fisher Scientific Cat\# A-21042 Lot\# RRID: AB_2535711. Recognizes type 2B antibody). The slides were washed 3 times again with PBS $1 \mathrm{x}$ and mounted using VectaShield anti-fade solution (Vector Laboratories Cat\# H-1000 Lot\# RRID:AB_ 2336789). Images were acquired using an air objective (10x, 0.25NA) in a fluorescence microscope (Leica DM2500) coupled to a Leica DFC 345FX camera and visualized in a computer. Excitation light came from a 100W Hg lamp, and an FITC filter was used to collect emitted light. Whole muscle cross sections were imaged for analysis. Each fiber type was expressed as a percentage of the total number of fibers counted in a whole muscle section. Stained sections were also used to analyze the CSA of type identified muscle fibers. Each antibody was validated using appropriate negative controls, which included sections not incubated with primary antibodies (data not shown).

\subsection{Reverse transcription and $q P C R$}

The EDL and soleus muscles were rapidly removed from animals, immersed in RNA latter solution (Sigma-Aldrich) to avoid RNA degradation, and stored for $24 \mathrm{~h}$ at $4{ }^{\circ} \mathrm{C}$ and at $-20^{\circ} \mathrm{C}$ until processing. Total RNA was extracted using TRIzol reagent (Invitrogen, San Diego, CA) and treated with DNAse Amplification Grade (RNase-free) (Sigma AMP-D1). After reverse transcription (RT-PCR) using the M-MLV enzyme (M-MLV RT, Promega, M1705), 40 ng of the generated cDNA was used for qPCR. The endogenous GAPDH (internal control) Fw: TGCG ACTTCAACAGCAACTC; Rv: ATGTAGGCCATGAGGTCCAC; Myogenin Fw: CACTCCCTTACGTCCATCGT; Rv:CAGGACAGCCCCACTTA AAA;MyoDFw:GGCCACTCAGGTCTCAGGTGT;Rv:TGTTGCACTACACA GCATGCCT; Pax-7 Fw: AAAAGCACCAAGCCAAGACC; Rv: GCACACAT CCCACTCACACC; PGC1- $\alpha 1$ Fw: CCCTGCCATTGTTAAGACC; Rv: TGC TGCTGTTCCTGTTTTC; MTND-1 Fw: GTTGGTCCATACGGCATTTT; Rv: TGGGTGTGGTATTGGTAGGG; Atrogin1 Fw: GCAGAGAGTCGGCAA GTC; Rv: CAGGTCGGTGATCGTGAG and MuRF1 Fw: TGGAAACGCTA TGGAGAACC; Rv: ATTCGCAGCCTGGAAGATG were amplified. SYBR green reagent (SYBR ${ }^{\circ}$ Green PCR Master Mix, Applied Biosystems) was used in ViiA $^{\mathrm{TM}} 7$ System (Applied Biosystems) real-time cycler that allows automatic melting curve analysis. A single melt peak for each reaction confirmed the identity of each PCR product. The relative comparative Cycle Threshold (CT) method was applied to compare gene expression levels between groups, using the equation (2) ${ }^{-\Delta \Delta C T}$ (Pcr and Pfaffl, 2001). The expression level of WT and VAChT-KD ${ }^{\mathrm{HOM}}$ genes were normalized to GAPDH as an internal control and no differences were found in GAPDH CTs between EDLs from WT and VAChT$\mathrm{KD}^{\mathrm{HOM}}$ mice. Myogenin (WT: $13.2 \pm 0.1$ and VAChT-KD ${ }^{\mathrm{HOM}}$ : $13.2 \pm 0.28)$. MyoD (WT: $13.1 \pm 0.1$ and VAChT-KD $^{\text {HOM }}$ : $13.1 \pm 0.27$ ). MTND-1 and Pax-7 (WT: $13.4 \pm 0.1$ and VAChT$\mathrm{KD}^{\mathrm{HOM}}$ : $13.9 \pm 0.32$ ). Atrogin-1, MuRF-1 and PGC1- $\alpha$ (WT: $13.4 \pm 0.08$ and VAChT-KD ${ }^{\text {HOM }}: 14 \pm 0.38$ ). Soleus: Myogenin (WT: $14.8 \pm 0.3$ and VAChT-KD ${ }^{\text {HOM }}: 14.1 \pm 0.2$ ). MyoD (WT: $14.5 \pm 0.3$ and VAChT-KD ${ }^{\mathrm{HOM}}$ : $14 \pm 0.2$ ). MTND-1 and Pax-7 (WT: $14.8 \pm 0.3$ and VAChT-KD ${ }^{\text {HOM }}: 14.4 \pm 0.2$ ). Atrogin-1, MuRF-1 and PGC1- $\alpha$ (WT: $14.7 \pm 0.3$ and VAChT-KD ${ }^{\text {HOM }}: 14.1 \pm 0.2$ ). Expression changes reflect fold differences between WT mice (control) and VAChT-KD ${ }^{\mathrm{HOM}}$ mice. RNA sequences are available at GenBank data base in: (https:// www.ncbi.nlm.nih.gov/genbank/).

\subsection{Transmission electron microscopy (TEM)}

For ultrastructure analyses, we used the protocol described by Rodrigues et al. (2013). Briefly, EDL and soleus muscles from WT and VAChT-KD ${ }^{\mathrm{HOM}}$ were fixed by ice-cold modified Karnovsky fixative (4\% paraformaldehyde and $2.5 \%$ glutaraldehyde in $0.1 \mathrm{M}$ sodium cacodylate buffer) and maintained in this solution for at least $24 \mathrm{~h}$ at $4{ }^{\circ} \mathrm{C}$. After fixation, samples were washed with cacodylate buffer (0.1 M- EMS), cut into several pieces, post-fixed in reduced osmium ( $1 \%$ osmium tetroxide in cacodylate buffer containing $1.6 \%$ potassium ferrocyanideEMS), contrasted en bloc with uranyl acetate (2\% uranyl acetate in deionized water- EMS), dehydrated through an ascending series of ethanol solutions followed by acetone and embedded in EPON 812 resin kit (EMS). Blocks were sectioned $(50 \mathrm{~nm})$ and collected on 200 or 300 mesh copper grids and contrasted with lead citrate (EMS). Sections were viewed with a Tecnai- G2-Spirit-FEI/Quanta electron microscope (120 kV Philips) located at Microscopy Center - UFMG.

\subsection{Behavioral tests}

\subsubsection{Open field}

The open field test was used to analyze spontaneous locomotor activity (Ferreira-Vieira et al., 2014; Sousa et al., 2006). The test was performed in a box $(50 \times 50 \mathrm{~cm})$ with the floor divided into 16 equal squares. The mice were individually placed in the back corner of the left side and allowed to explore the open field for 300s. The spontaneous locomotor activity was measured using sensors located at the base of the boxes connected to a computer where a software automatically determined the number of segments crossed, known as crossing (horizontal locomotion) (Vianna et al., 2000).

\subsubsection{Wire-hang}

The wire-hang test is a useful tool to evaluate motor strength in rodents, and the experiments were performed according to Sango et al. (1996) and Prado et al. (2006). Mice were habituated at the behavioral room $2 \mathrm{~h}$ before the test. We placed each animal individually in the top of a wire cage lid $(22 \times 22 \mathrm{~cm})$ and then the lid was gently turned upside down by the investigator. The latency of mice to lose their grip and fall off the lid was visually evaluated in three trials with a cutoff time of 60 s.

\subsubsection{Rotarod}

The rotarod test was used to assess motor coordination in our experimental model (Ingram et al., 1981). The apparatus consists of a rotating cylinder. The time animals take to fall from the rotating rod is registered automatically. We used the protocol described by Prado et al. (2006) with minor modifications to account for the age of the mice tested in this study. First, mice were acclimated three consecutive days to the rotarod apparatus (Insight Equipments, Ribeirão Preto, Brazil) with the device turned off. Second, each mouse was gently placed on the rod, and the rotation speed was set to $7 \mathrm{rpm}$. The training session consisted of three trials. Four hours later, animals were tested using a non-accelerating protocol (rotation maintained at $7 \mathrm{rpm}$ ). The performance of each animal on the rotarod represents the average of three independent tests.

\subsection{Maximal incremental test (M.I.T)}

An electric treadmill (EP - 132 - INSIGHT, Ribeirão Preto, Brazil) was used to evaluate mice maximal aerobic capacity. The initial speed was set at $10 \mathrm{~cm}$ per seconds $(\mathrm{cm} / \mathrm{s})$ for $5 \mathrm{~min}$ through five days (Familiarization Period). The Maximal Incremental Test (MIT) starts with the speed at $10 \mathrm{~cm} / \mathrm{s}$ then increases $5 \mathrm{~cm} / \mathrm{s}$ every $3 \mathrm{~min}$, at a $5 \%$ grade, until the animal stops running and is fatigued. Fatigue is defined by the refusal of the mouse to continue moving on the treadmill belt more than $10 \mathrm{~s}$. A mild electrical stimulus $(0.2 \mathrm{~mA})$ was applied to the mice that stepped off the treadmill to keep them exercising. For oxygen consumption mice were weighed and placed individually into the gas chamber coupled to the test treadmill using continuous recorders of oxygen consumption $\left(\mathrm{VO}_{2}\right)$ with an open-flow indirect calorimeter (LE405 Gas Analyzer, Panlab Harvard Apparatus, Spain). $\mathrm{VO}_{2}\left(\mathrm{mlO}_{2} /\right.$ 
$\mathrm{kg} / \mathrm{min}$ ) was continuously recorded on-line, every minute at rest and during the fatiguing exercise protocol (exercise protocol) and then analyzed using a computerized system (Metabolism V 2.2.01, Harvard Apparatus, Spain). In the first $30 \mathrm{~min}$, the animals were placed in the treadmill coupled to a gas chamber for measurements of the basal $\mathrm{VO}_{2}$. Immediately after this time, the treadmill was turned on and mice started to run following the test protocol. At the end of the test the $\mathrm{VO}_{2}$ peak was selected for analysis. Workload (W) was calculated as $\mathrm{W}=$ [body weight $(\mathrm{kg})] \times$ [time to fatigue $] \times$ [treadmill speed $(\mathrm{m} /$ $\min )] \times[\sin \theta$ (treadmill inclination) $]$.

\subsection{Pharmacological treatment}

Six month old WT and VAChT-KD ${ }^{\mathrm{HOM}}$ mice were treated with the acetylcholinesterase inhibitor pyridostigmine (Sigma-Aldrich) (i.p., $1 \mathrm{mg} / \mathrm{kg}$ ) for 28 days with two doses per day, according to Prado et al. (2006). At the end of the treatment period, animals were sacrificed, then EDL and soleus muscles were excised for histology analysis as described above.

\subsection{Statistical analysis}

All data were analyzed using Microsoft Excel and GraphPad Prism 5. The histology data represent the mean \pm SEM of least 500 muscle fibers CSA summarized in tables. Before defining the statistical tests, data was evaluated by the Kolmogorov-Smirnov normality test to address whether or not the data followed a Gaussian distribution. Statistical significance was evaluated using the unpaired Student's t-test when data was normally distributed or Mann-Whitney test for non-Gaussian distribution. One-way ANOVA or Kruskal-Wallis, and a post hoc Newman Kulls or Dunn's multiple comparison test was performed when appropriate, as described in the text. Values of $\mathrm{p} \leq 0.05$ were considered significant. All behavioral, molecular, electron microscopy and maximal incremental tests experiments were conducted with researchers "blind" to the genotypes of the mice, except for histological and fiber typing analysis. Each genotyped animal was assigned a code that was revealed to the investigator after completing analysis. In this work we used between $n=3-7$ animals per genotype for each data set to detect a difference at $95 \%$ confidence interval $(\mathrm{a}=0.05)$ and 0.8 power. The exact $\mathrm{n}$ for each experimental procedure is described in the figure legends, as well as $\mathrm{p}$ values. All data points were treated as outliers and excluded from the data analysis using the Graph Pad QuickCalcs outlier calculator available at (https://graphpad.com/ quickcalcs/Grubbs1.cfm).

\section{Results}

First, we evaluated the long-term effects of decreased ACh on the morphology of muscle fibers in the gastrocnemius muscle. Gastrocnemius muscle cross-sections from VAChT-KD ${ }^{\mathrm{HOM}}$ and wild type (WT) mice were stained with antibodies against different fiber types and with toluidine blue to visualize muscle fiber subtypes and their cross-sectional area (CSA), respectively (Fig. 1A-B). We found that muscle fibers in the gastrocnemius muscle of VAChT-KD ${ }^{\mathrm{HOM}}$ are on average 14\% smaller compared to WT mice (Fig. 1C-D). We also found fewer type $2 \mathrm{~B}$ fibers in the gastrocnemius muscles of VAChT-KD mice $(28 \pm 1.46 \%)$ compared to WT $(48.4 \pm 5.07 \%)$. Interestingly, we found more type $2 \mathrm{X}$ in VAChT-KD ${ }^{\mathrm{HOM}}$ mice $(34.7 \pm 5.1 \%)$ compared
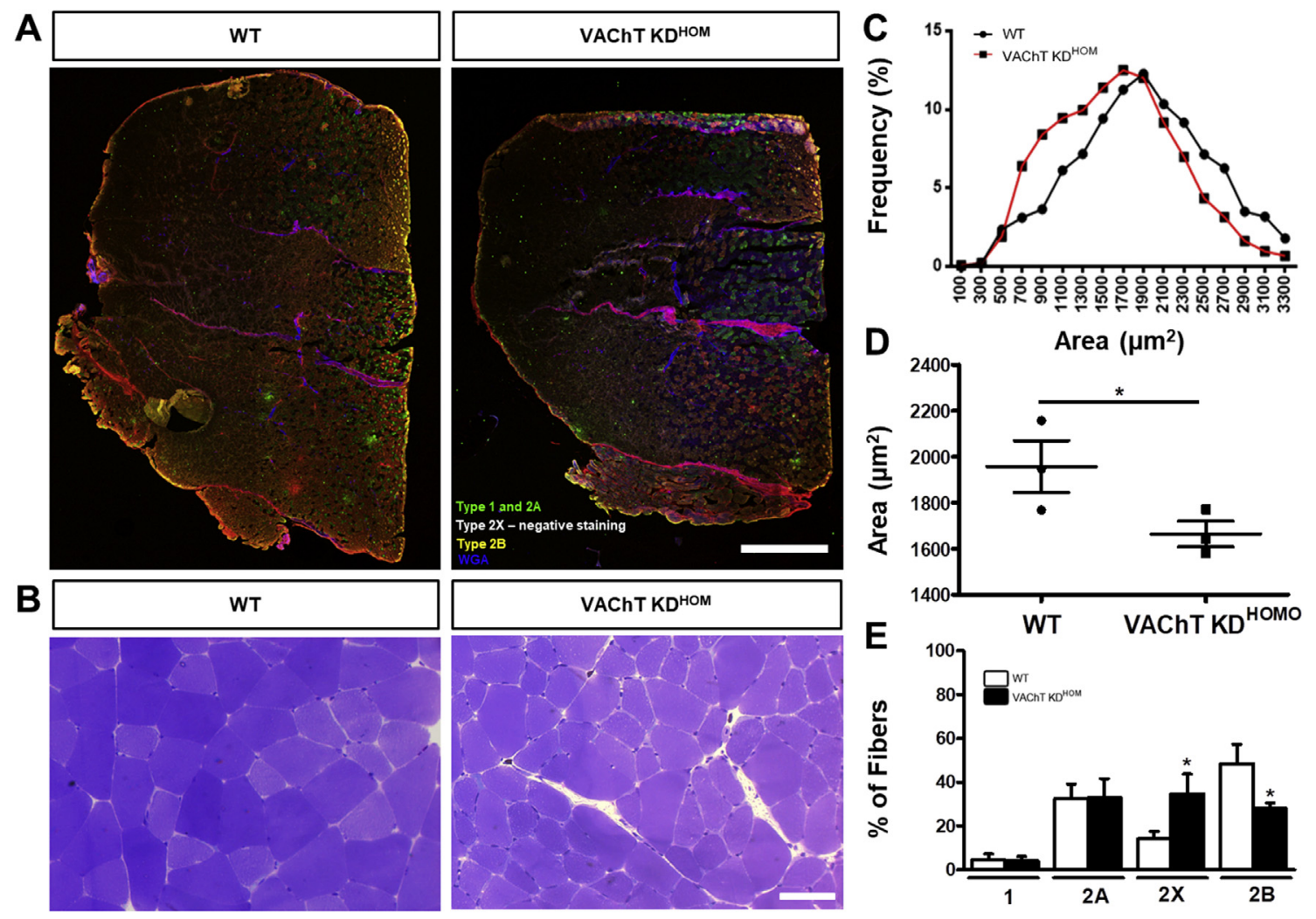



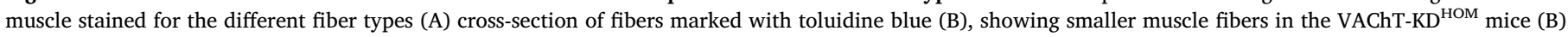

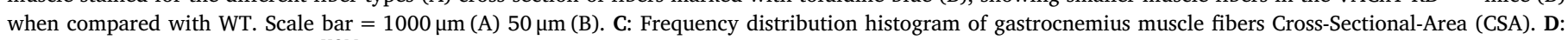

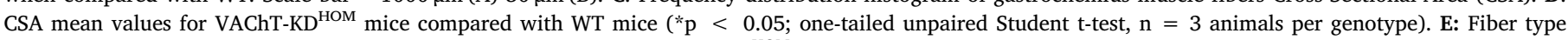

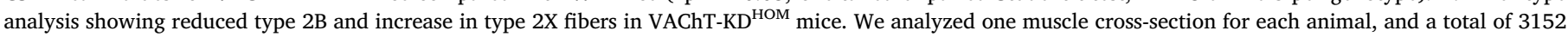

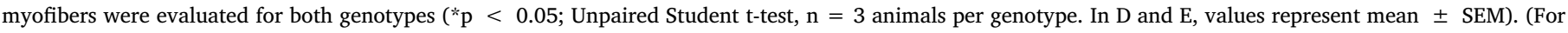
interpretation of the references to colour in this figure legend, the reader is referred to the Web version of this article.) 
to WT $(14.2 \pm 1.91 \%)$. We next examined muscle fibers in the predominantly fast-twitch extensor digitorum longus (EDL) muscle. Muscle fibers in the EDL were on average $22 \%$ smaller in VAChT-KD ${ }^{\mathrm{HOM}}$ mice compared to WT (Fig. 2A and Table 1). This overall reduction in muscle fiber size was due to decreased CSA in types 2X and 2B fibers in the EDL of VAChT-KD ${ }^{\mathrm{HOM}}$ (Fig. 2B-D and Table 1). The EDL muscle is composed mainly of fast-glycolytic muscle fibers (type $2 \mathrm{X}$ and $2 \mathrm{~B}$ ) and few fast oxidative-glycolytic muscle fibers (type 2A) (Bloemberg and Quadrilatero, 2012). Interestingly, the EDL muscles in VAChT-KD ${ }^{\mathrm{HOM}}$ mice also have fewer muscle fibers (Table 1), suggesting that either muscle fibers failed to form or degenerate postnatally. Based on this observation, we determined the number of each muscle fiber type populating the EDL muscle in VAChT-KD ${ }^{\mathrm{HOM}}$ and WT mice. While Type $2 \mathrm{~B}$ fibers were reduced, type $2 \mathrm{X}$ fibers were increased in VAChT-KD ${ }^{\mathrm{HOM}}$ mice compared with WT mice (Table 1). This analysis showed similar numbers of type $2 \mathrm{~A}$ muscle fibers between genotypes demonstrating that these changes were specific to fast glycolytic muscle fibers (2B and $2 \mathrm{X}$ ). The shifts in type $2 \mathrm{X} / 2 \mathrm{~B}$ ratio in the gastrocnemius and EDL muscles suggest that reduced cholinergic transmission either causes type $2 \mathrm{~B}$ to dedifferentiate into type $2 \mathrm{X}$ or slows the differentiation of type $2 \mathrm{X}$ into type $2 \mathrm{~B}$ muscle fibers.

The reduced size and number of muscle fibers in the EDL muscle of VAChT-KD ${ }^{\mathrm{HOM}}$ mice also indicates that reduced cholinergic transmission results in the activation of pro-atrophy genes. To look into this possibility, we examined levels of Atrogin-1 and MuRF1, both involved in the activation of the ubiquitin-proteasome system (Sacheck et al., 2004). Unexpectedly, Atrogin-1 is reduced and MuRF-1 remains unchanged in the EDL muscle of VAChT-KD ${ }^{\mathrm{HOM}}$ compared with WT mice (Table 1). We then examined levels of Pax-7, Myogenin, and MyoD, three genes important for muscle biogenesis and maintenance. We found MyoD and Myogenin reduced in the EDL muscles of VAChT$\mathrm{KD}^{\mathrm{HOM}}$ mice (Table 1). However, levels of Pax-7 remain unchanged in the EDL muscles of VAChT-KD ${ }^{\mathrm{HOM}}$ mice (Table 1). Next, we examined levels of two mitochondria-related genes important in skeletal muscles. PGC1- $\alpha$ promotes mitochondrial biogenesis (Yoon et al., 2001) and MTND-1 is a mitochondrial DNA (mtDNA) encoding complex I gene associated with mitochondrial respiratory chain (Mimaki et al., 2012). No significant difference was found in PGC1- $\alpha$ expression between
A



B

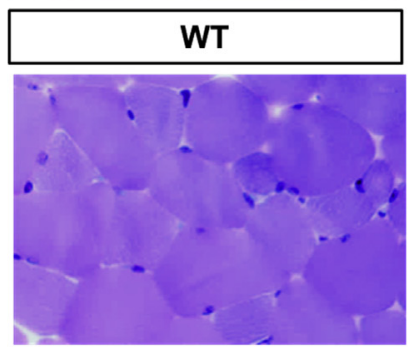

C
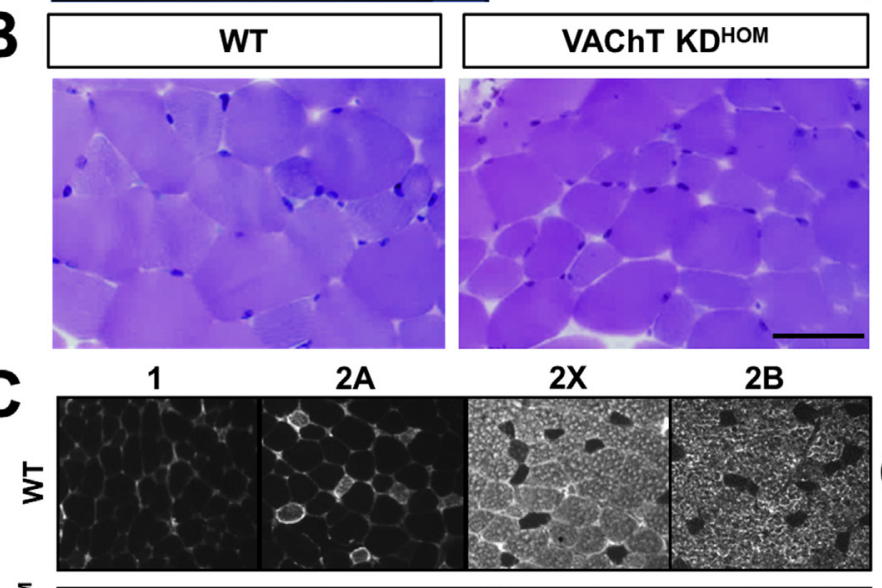
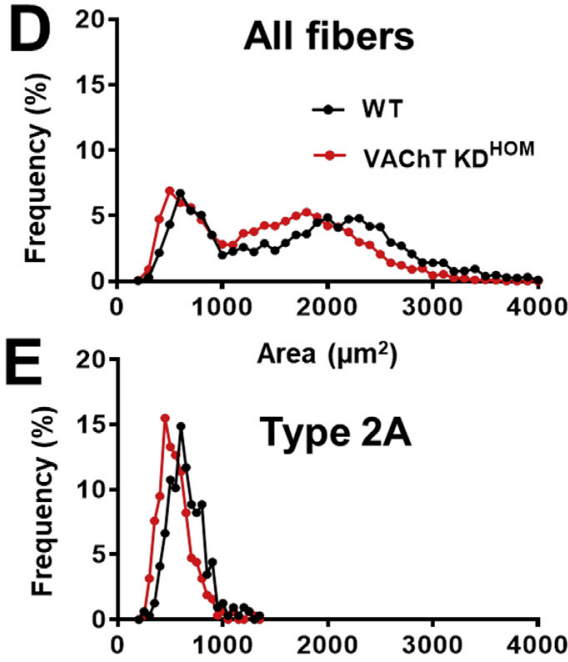

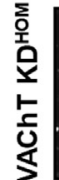
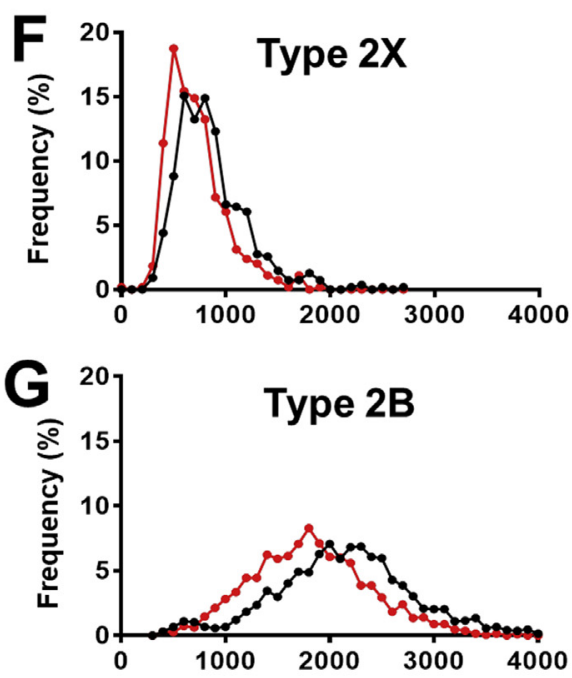

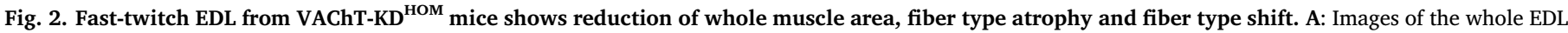










7 VAChT-KD ${ }^{\mathrm{HOM}}$ mice. (For interpretation of the references to colour in this figure legend, the reader is referred to the Web version of this article.) 
VAChT-KD ${ }^{\text {HOM }}$ mice and WT mice (Table 1). However, MTND-1 was reduced by $36 \%$ in VAChT-KD ${ }^{\mathrm{HOM}}$ mice (Table 1 ). These findings show that myogenesis and mitochondria function are impaired, and potentially contribute to the decreased number and size of muscle fibers in the EDL muscles of VAChT-KD ${ }^{\mathrm{HOM}}$ mice.

The soleus muscle is quite different from the EDL muscle in several respects. It is primarily composed of slow-twitch muscle fibers, it is tonically active, and functions in maintaining posture (Di Giulio et al., 2009). We thus asked if reducing ACh levels has a similar effect on the soleus as observed above in the EDL muscles. In stark contrast to the EDL muscle, we found that muscle fibers are approximately $11 \%$ larger in the soleus muscle of VAChT-KD ${ }^{\mathrm{HOM}}$ mice compared to WT mice (Fig. 3D and Table 2). Both type 1 and 2A muscle fibers were enlarged by $8 \%$ and $17 \%$, respectively in VAChT-KD ${ }^{\mathrm{HOM}}$ mice compared to WT mice (Fig. 3C-G and Table 2). Moreover, the ratio of type 1 to type $2 \mathrm{~A}$ muscle fiber is higher in the soleus muscle of VAChT $\mathrm{KD}^{\mathrm{HOM}}$ compared to WT mice (Table 2). Despite the increased size of muscle fibers, the overall size of the soleus muscle was indistinguishable between VAChT$\mathrm{KD}^{\mathrm{HOM}}$ and WT mice (Fig. 3A and Table 2). The overall size of the soleus muscle remains unchanged because it contains fewer, yet larger, muscle fibers in VAChT-KD ${ }^{\mathrm{HOM}}$ compared to WT mice (Table 2).

To further examine the impact of reducing $\mathrm{ACh}$ on the soleus muscle, we again assessed expression levels of genes associated with muscle atrophy, biogenesis, and maintenance. In contrast to the EDL muscle, Atrogin-1 and MuRF1 levels are 1.7 and 1.4 fold higher, respectively, in VAChT-KD ${ }^{\mathrm{HOM}}$ mice (Table 2). Likewise, Pax-7 and MyoD are 2.9 and 2 fold higher, respectively, in the soleus muscle of VAChT$\mathrm{KD}^{\mathrm{HOM}}$ mice (Table 2). Additionally, the metabolic modulators, PGC1- $\alpha$ and MTND-1, are both increased in the soleus muscle of VAChT-KD ${ }^{\mathrm{HOM}}$ mice (Table 2). Together, these data show that decreasing ACh levels has a different effect on the soleus muscle, and particularly on type 1 muscle fibers, compared to the EDL muscle and fast type muscle fibers.

We used transmission electron microscopy (TEM) to visualize the subcellular composition of slow and fast-twitch muscles under reduced cholinergic transmission. In the EDL muscle of WT mice, as expected, the Z-line (white arrows) (Fig. 4A), triads (sarcoplasmic reticulum- SR and T-tubules) (white arrows-head) (Fig. 4B), mitochondria (red arrows-head) (Fig. 4B), and sarcomeres (red asterisks) (Fig. 4B) appear


B
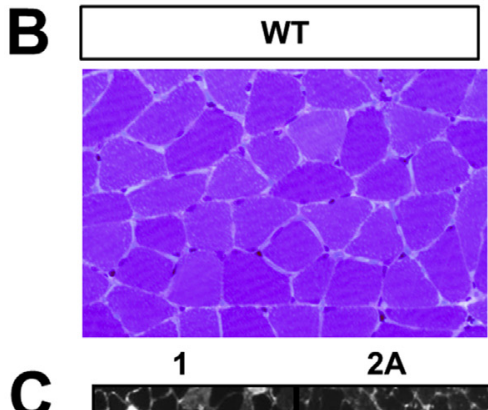
1 2A
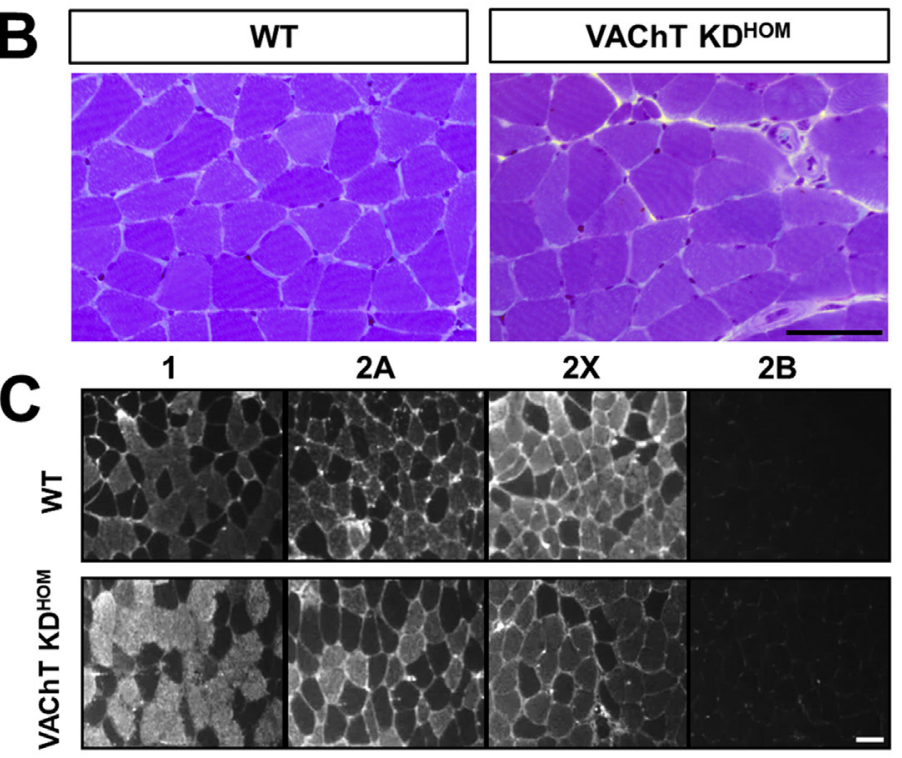

2X: unstained




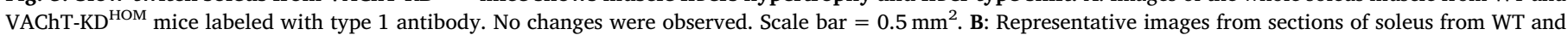





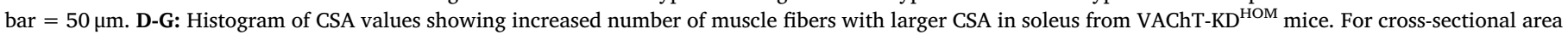

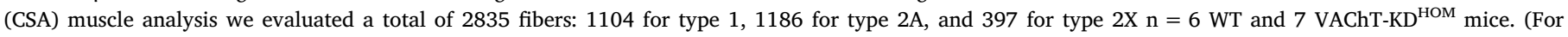
interpretation of the references to colour in this figure legend, the reader is referred to the Web version of this article.) 




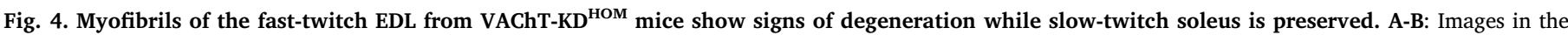

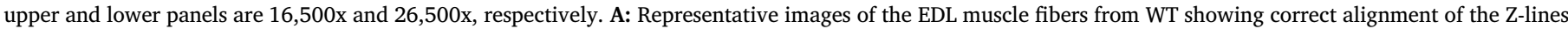

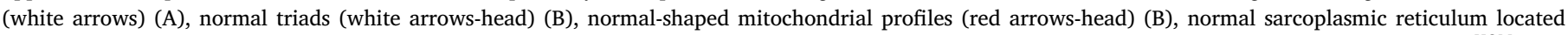

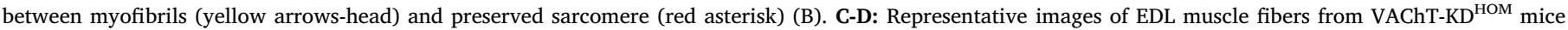

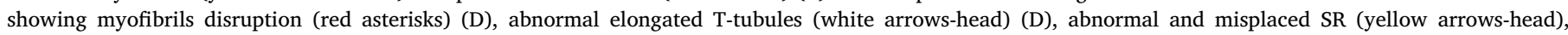







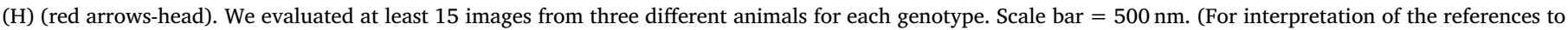
colour in this figure legend, the reader is referred to the Web version of this article.)

normal. In contrast, muscle fibers of the EDL from VAChT-KD ${ }^{\mathrm{HOM}}$ mice present discontinuous Z-lines (white arrows) (Fig. 4C) and disruption of myofilaments (separation of the thin and thick myofilaments) of some sarcomeres (red asterisks) (Fig. 4D). Quantitatively, the number of disrupted sarcomeres is 6.2 times higher in VAChT-KD ${ }^{\mathrm{HOM}}$ mice compared to WT mice (WT: $5.7 \pm 3.3$ and VAChT-KD ${ }^{\mathrm{HOM}}: 35.6 \pm 9.1 \%$, $\mathrm{p}=0.03$ ). These muscle fibers also exhibit abnormal T-tubules, which are more elongated than normal, and lack typical triads (white arrowshead) (Fig. 4D). The SR also exhibits abnormal, swelled, and misplaced vacuole-like structures (yellow arrows-head) (Fig. 4D). Moreover, we found elongated mitochondrial profiles located in the regions of muscle fibers associated with degraded myofibril regions (red arrows-head) (Fig. 4D). In stark contrast to the EDL muscle, fibers in the soleus muscle from VAChT-KD ${ }^{\mathrm{HOM}}$ mice exhibit preserved components, such as correct alignment and continuity of the Z-lines (white arrows) (Fig. 4E-G), and sarcomere integrity (red asterisk) (Fig. 4F-H). In agreement with increased PGC1- $\alpha$ and MTND-1 levels, mitochondria are more prevalent in muscle fibers in the soleus muscle of VAChT$\mathrm{KD}^{\mathrm{HOM}}$ compared to WT mice (Fig. 4G-H).

To assess the function of the gastrocnemius, soleus, and EDL muscles, we performed a series of behavior and oxygen consumption tests in VAChT-KD ${ }^{\mathrm{HOM}}$ and WT mice. Oxygen consumption while resting and under maximal intensity was measured using a maximal incremental test (MIT). The duration, distance, maximum velocity (Vmáx), the work, and oxygen handling parameters were evaluated. We found a significant reduction in the MIT duration and distance (Table 3) in VAChT-KD ${ }^{\mathrm{HOM}}$ mice. The maximum velocity is also reduced (Table 3). Additionally, the work performed is significantly reduced in VAChT-

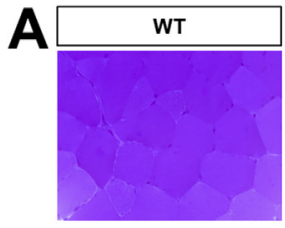

B

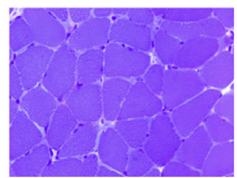

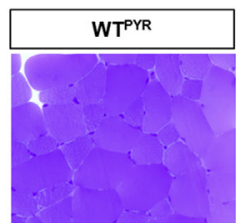

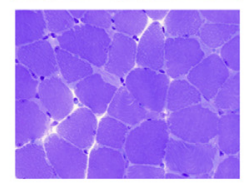

C

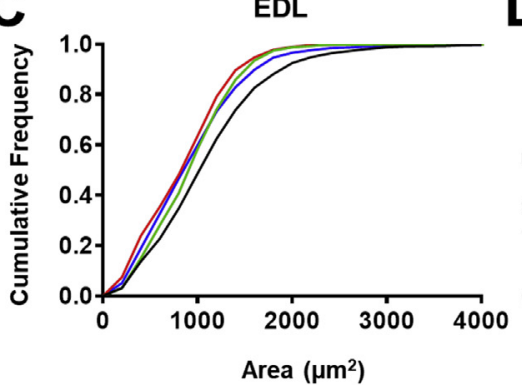

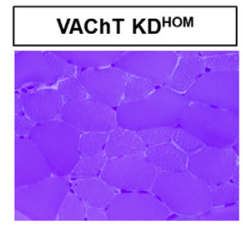

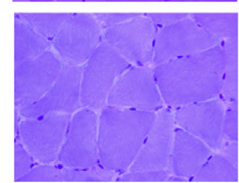

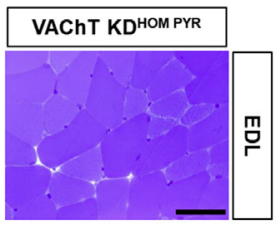

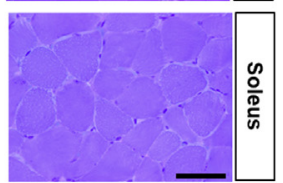

D



Fig. 5. Pyridostigmine (PYR) treatment partially reverses morphology alterations in EDL and soleus muscles in VAChT-KD $^{\text {HOM }}$ mice. A-B: Images of EDL (A) and soleus (B) muscle fibers from WT and VAChT-KD ${ }^{\mathrm{HOM}}$ mice treated and non-treated with PYR. C. Cumulative frequency of muscle fibers areas of the EDL from WT and VAChT-KD ${ }^{\mathrm{HOM}}$ mice showing VAChT-KD ${ }^{\mathrm{HOM}}$-PYR partially restoring muscle fibers to WT values. D. In the Soleus, VAChT-KD ${ }^{\text {HOM }}$-PYR partially restored the sizes of its muscle fibers. For the EDL and soleus at least 1130 and 1573 myofibers, respectively, were analyzed from three animals per genotype/treatment. 
$\mathrm{KD}^{\mathrm{HOM}}$ mice compared to WT mice (Table 3). Despite these differences, the oxygen consumed is the same between genotypes while resting and under MIT (Table 3). This finding is more surprising given that VAChT$\mathrm{KD}^{\mathrm{HOM}}$ mice weigh significantly less than WT mice (Table 3 ).

Given that skeletal muscles may be similarly affected in individuals with VAChT mutations, we tested if increasing the levels of ACh at the synaptic cleft reverses the functional and morphological features found in VAChT-KD ${ }^{\mathrm{HOM}}$ mice. To address this, WT and VAChT-KD ${ }^{\mathrm{HOM}}$ mice were treated with the cholinesterase inhibitor pyridostigmine $(1 \mathrm{mg} / \mathrm{kg}$, twice daily) for 28 days. We then compared the muscle fiber average CSA among the different treatments and genotypes in the EDL and soleus muscles. In this case, we specifically compared the distribution of muscles sizes using a cumulative frequency graph (Fig. 5C and D) due to the inherent high variability of muscle sizes across genotypes and following pyridostigmine treatments. This analysis revealed that pyridostigmine partially restores the size of muscle fibers in the EDL of VAChT-KD ${ }^{\text {HOM }}$ mice (Table 4 and Fig. 5A and C). Although the treatment reduces the CSA of WT-treated compared with non-treated WT mice (Table 4 and Fig. 5C), the size of muscle fibers in non-treated VAChT-KD ${ }^{\mathrm{HOM}}$ mice remains reduced compared to treated WT mice (Fig. 5A and C). In the soleus muscle, pyridostigmine partially reduces the hypertrophy observed in VAChT-KD ${ }^{\mathrm{HOM}}$ muscle fibers (Fig. 5B and D). These findings led us to ask if pyridostigmine treatment improves motor function in VAChT-KD ${ }^{\mathrm{HOM}}$ mice. We found that animals treated with pyridostigmine perform better in the open-field task (Table 4). VAChT-KD ${ }^{\mathrm{HOM}}$ mice treated with pyridostigmine did not perform better in the rotarod or wire-hanging test based on a Kruskal-Wallis with Dunn's multiple comparison test. However, intra-genotype comparisons revealed that VAChT-KD ${ }^{\mathrm{HOM}}$ mice treated with pyridostigmine perform 2.5 times better on both tests compared with vehicle treated VAChT$\mathrm{KD}^{\mathrm{HOM}}$ mice (Table 4). These differences were significant using a twotailed unpaired student t-test.

\section{Discussion}

Most CMS cases are related to mutations in postsynaptic proteins and the prevalence of pre-synaptic mutations are very rare and, until now, only found in SNAP25B (Shen et al., 2014), Synaptotagin-2 (Herrmann et al., 2014), Synaptobrevin-1 (Shen et al., 2017), MUNC13-1 (Engel et al., 2016), ChAT (Byring et al., 2002; Ohno et al., 2001), and CHT- 1 (Bauché et al., 2016). However, recent reports revealed congenital myasthenia in individuals caused by mutations in the VAChT gene (Aran et al., 2017; Schwartz et al., 2018; O'Grady et al., 2016). Using VAChT mouse models to study CMS (VAChT-KD ${ }^{\text {HOM }}$ and VAChTKnockout), our group has found motor (Prado et al., 2006), cardiac (Lara et al., 2010), and synaptic (de Castro et al., 2009; Lima et al., 2010; Prado et al., 2006; Rodrigues et al., 2013) alterations that resemble some of the features later discovered in patients with VAChT mutations (O'Grady et al., 2016; Aran et al., 2017; Schwartz et al.,
2018). For example, we previously showed that NMJs in the diaphragm from VAChT-KD ${ }^{\mathrm{HOM}}$ mice exhibit several abnormalities, including altered recycling of synaptic vesicles (Rodrigues et al., 2013). Those published findings led us to hypothesize that reduced cholinergic transmission may differentially affect the size and biochemical properties of muscle fiber subtypes. Thus, in the present study, we investigated the impact of lowering ACh on the fast-contracting EDL, the slow-contracting soleus, and the gastrocnemius muscles.

\subsection{Fast type muscle fibers are preferentially affected by reduced cholinergic transmission}

Different mouse models of neuromuscular disorders have revealed that fast-twitch skeletal muscles are more susceptible to atrophy than slow-contracting muscles (Harandi et al., 2014; Wang and Pessin, 2013; Biral et al., 1989). In addition, denervation or tetrodotoxin (TTX) blockade of nerve impulses preferentially cause the atrophy of fast type muscle fibers in the diaphragm (Aravamudan et al., 2006) and gastrocnemius muscles (Zhan and Sieck, 1992). We found that fast-twitch muscle fiber types (2B, 2X) are smaller in the EDL muscle of VAChT$\mathrm{KD}^{\mathrm{HOM}}$ compared with WT mice using light microscopy. Ultrastructural analysis corroborated this finding, and revealed that myofibrils degrade in muscle fibers of the EDL muscle from VAChT-KD ${ }^{\mathrm{HOM}}$ mice. Interestingly, the EDL muscle of VAChT-KD ${ }^{\mathrm{HOM}}$ mice contained fewer type $2 \mathrm{~B}$ and more type $2 \mathrm{X}$ fibers compared to WT mice. This shift in the ratio of muscle fiber types in fast muscles has also been observed in aged animals (Larsson and Ansved, 1995; Larsson et al. 1993, 1995), where cholinergic transmission has been found to also be altered.

In addition to cellular changes, reduced cholinergic transmission also affects the molecular composition of the EDL muscle. We found that Atrogin-1 is reduced while no changes were found in MuRF1 in the EDL muscle of VAChT-KD ${ }^{\mathrm{HOM}}$ mice. This finding was surprising because muscle fibers atrophy in the EDL muscle of adult VAChT-KD ${ }^{\mathrm{HOM}}$ mice, and Atrogin-1 and MuRF1 promote muscle atrophy when induced (Bodine and Baehr, 2014). However, the pro-myogenic genes MyoD and myogenin are reduced in the EDL of VAChT-KD ${ }^{\mathrm{HOM}}$ mice. In addition to playing critical roles in muscle biogenesis, myogenin and MyoD also regulate the expression of Atrogin-1 and MuRF1 (Bonaldo and Sandri, 2013; Hyatt et al., 2003; Moresi et al., 2010). The observed reduction in myogenin, MyoD, and Atrogin-1 expression in the EDL muscle from VAChT-KD ${ }^{\mathrm{HOM}}$ suggests that reduced cholinergic transmission inhibits myogenesis but also atrophy in adult fast type muscles. These findings thus raise the possibility that myogenesis is impaired during developmental stages and/or the growth of newly formed muscle fibers is inhibited in the EDL of adult VAChT-KD ${ }^{\mathrm{HOM}}$ mice, potentially accounting for fewer and smaller muscle fibers. This is a possibility that can be assessed in future studies designed to analyze the number and size of muscle fibers during development in addition to myogenin and Myod expression in VAChT-KD ${ }^{\mathrm{HOM}}$ mice. If the formation and growth of

Table 4

Results of the treatment with Pyridostigmine (PYR) on mice muscle histology and behavior.

\begin{tabular}{|c|c|c|c|c|c|}
\hline HISTOLOGY & WT & $\mathrm{WT}^{\mathrm{PYR}}$ & VAChT-KD ${ }^{\text {HOм }}$ & VAChT-KD ${ }^{\text {HOM PYR }}$ & Statistics \\
\hline Soleus - CSA $\left(\mu \mathrm{m}^{2}\right)$ & $1199 \pm 364$ & $1031 \pm 59.1$ & $1535 \pm 168.7$ & $1258 \pm 97.7$ & $\mathrm{NS}^{\#}$ \\
\hline Open-field & $95 \pm 27$ & $106.4 \pm 18$ & $46 \pm 11^{\mathrm{ab}}$ & $83.4 \pm 16.7^{c}$ & $\mathrm{p}=0.0007^{\#}$ \\
\hline Rotarod (s) & $225 \pm 100$ & $271 \pm 64$ & $104 \pm 60.3^{\mathrm{b}}$ & $263 \pm 29$ & $\mathrm{p}=0.03$ \\
\hline Wire-hang (s) & $28.4 \pm 10$ & $39.2 \pm 6.2$ & $5.0 \pm 1.1^{\mathrm{ab}}$ & $12 \pm 2.1$ & $\mathrm{p}=0.0007$ \\
\hline
\end{tabular}

Statistical analysis was deployed to compare differences between at least $3 \mathrm{WT}$ and 3 VAChT-KD ${ }^{\text {HOM }}$ mice. Values represent Mean \pm SEM. Statistics for rotarod and wire-hang: Kruskal-Wallis with Dunn's multiple comparison test. For the EDL, at least 1130 myofibers in a $\mathrm{n}=3$ animals per genotype/treatment were analyzed. In soleus, at least 1573 myofibers in a $\mathrm{n}=3$ animals per genotype/treatment were analyzed. For behavior $\mathrm{n}=5$ animals per genotype/treatment. ${ }^{\text {a }}$ Statistically different from WT; ${ }^{b}$ different from $\mathrm{WT}^{\mathrm{PYR}}{ }^{\mathrm{c}}{ }^{\mathrm{c}}$ different from VAChT-KD ${ }^{\mathrm{HOM}}$. \#One-way ANOVA followed by Newman-Keuls Multiple Comparison Test. 
muscle fibers is disrupted in the EDL muscle of VAChT-KD ${ }^{\mathrm{HOM}}$, it would resemble findings reported following analysis of the R6/2 mice model for Huntington's disease where muscle fiber maturation is also impaired and partly due to progressive Cl-channel defects (Miranda et al., 2017). Irrespective, our findings show that reducing cholinergic transmission by $65 \%$ is deleterious to fast type muscle fibers.

\subsection{Type 1 muscle fibers size increase under reduced cholinergic transmission}

In contrast to the EDL, reduced cholinergic transmission causes muscle fibers in the soleus to hypertrophy. This finding was unexpected because the soleus is a tonic muscle, and we thus expected that reducing ACh by $65 \%$ would be detrimental to the viability of the soleus muscle. What could then account for the increased size of muscle fibers in the soleus muscle? One possibility is that atrophy of the gastrocnemius increases the functional load on the soleus to maintain balance thereby leading to compensatory hypertrophy of muscle fibers in the soleus. This possibility is supported by published studies showing that compensatory hypertrophy occurs in the soleus muscle (Allen et al., 2001) (Hanzlíková et al., 1975; Minderis et al., 2016). Another possibility, not mutually exclusive, is that type 1 fibers, which make a large proportion of the soleus muscle, resist degeneration and instead hypertrophy when cholinergic transmission is reduced. In this regard, Pax-7 and MyoD are both increased in the soleus muscle of VAChT-KD ${ }^{\mathrm{HOM}}$ mice, both genes important for myogenesis. Thus, mechanical overload could promote the proliferation of Pax-7-expressing satellite cells, thereby leading to increased expression of myogenic factors. However, the increased oxidative profile of the soleus muscle in VAChT- $\mathrm{KD}^{\mathrm{HOM}}$ mice suggests an alternative possibility. In these mice, the soleus is populated by more type 1 muscle fibers and has augmented expression of PGC1- $\alpha$, and MTND-1. Accompanying these changes was a loss of type 2A muscle fibers, further indicating that muscle fibers with a fast type profile are more affected by reduced cholinergic transmission preferentially. These changes are also found in aged skeletal muscles, where there is a shift from fast to slow fiber types (Holloszy et al., 1991; Larsson and Ansved, 1995; Miljkovic et al., 2015; Thompson, 1994). Therefore, it may be possible that the changes observed in the soleus muscle of VAChT$\mathrm{KD}^{\mathrm{HOM}}$ mice are more indicative of a premature aged phenotype.

\subsection{Reduced cholinergic transmission impacts physical capacity}

Previous data has shown that mice with reduced VAChT expression perform worse than WT mice in running tests (Prado et al., 2006). Here, in addition to the treadmill test, we measured oxygen consumption, a gold standard for the evaluation of aerobic capacity (Petrosino et al., 2016; Silva et al., 2016; Speakman, 2013). Interestingly, despite the reduction in duration, distance, and Vmax, VAChT- $\mathrm{KD}^{\mathrm{HOM}}$ and WT mice consumed the same oxygen amount during the tests. This result may be due to the lower mechanical efficiency of the VAChT-KD ${ }^{\mathrm{HOM}}$ mice resulting from cardiac dysfunction (Lara et al., 2010).

\subsection{Pyridostigmine treatment reverses muscle pathology caused by reduced cholinergic transmission}

Ultimately, the increased availability of ACh in the synaptic cleft caused by pyridostigmine partially reverses EDL atrophy and soleus hypertrophy in our mice. In addition, performance in open field, rotarod, and wire hanging are partially improved in comparison with nontreated mice. Since pyridostigmine acts preferably at the level of the peripheral nervous system, these results indicate that the reduced performance in the tests is due to abnormalities in hind limb muscles, including those analyzed herein. In our pyridostigmine treated mice, we cannot rule out an effect of increased ACh availability induced by this cholinesterase inhibitor in presynaptic auto-receptors. Previous work has shown that pyridostigmine increases neurotransmitter released following each nerve impulse in a mouse nerve muscle preparation (Vizi and Somogyi, 1989). This effect is mediated by nicotinic autoreceptors with positive feedback in the NMJ (Bowman et al., 1990; Starke et al., 1989). In addition, several experiments have shown a modulatory effect of presynaptic ACh release by agonists and antagonists of presynaptic muscarinic receptors (Ganguly and Das, 1979; Wessler, 1989; Santafé et al., 2003). Future experiments will be needed to clarify this point. Importantly, the successful reversion of some of the muscle changes and performance improvement obtained with pyridostigmine treatment of VAChT- $\mathrm{KD}^{\mathrm{HOM}}$ mice have interesting implications for neuromuscular disorders, such as CMS. Indeed, a mild clinical improvement was observed in patients with a biallelic variant of the VAChT gene that were treated with pyridostigmine (O'Grady et al., 2016). Taken together, these data emphasize the importance of maintaining normal cholinergic activity for preserving the structure of skeletal muscle fibers, and ultimately motor function.

\section{Conflicts of interest}

We have no conflict of interest to declare.

\section{Acknowledgements}

This work was supported by grants from FAPEMIG [\#00271-13]; CNPq [\#467220/2014-0, \#475735/2013-7] and CAPES. Cristina Guatimosim is a Bolsista de Produtividade em Pesquisa (CNPq). Gregorio Valdez received support from the National Institutes of Health in the US (K01NS085071, R56AG051501 and 1R01AG055545). The authors acknowledge the Center for Acquisition and Processing of Images (CAPI) - ICB - Universidade Federal de Minas Gerais and the Microscopy Center at Universidade Federal de Minas Gerais for providing the equipments and technical support for experiments involving tissue processing and electron microscopy. We thank Dr. Enrrico Bloise for suggestions on gene analyses.

\section{Appendix A. Supplementary data}

Supplementary data related to this article can be found at https:// doi.org/10.1016/j.neuint.2018.07.002.

\section{References}

Allen, D.L., Harrison, B.C., Sartorius, C., Byrnes, W.C., Leinwand, L. a, 2001. Mutation of the IIB myosin heavy chain gene results in muscle fiber loss and compensatory hypertrophy. Am. J. Physiol. Cell Physiol. 280, C637-C645.

Aran, A., Segel, R., Kaneshige, K., Gulsuner, S., Renbaum, P., Oliphant, S., Meirson, T., Weinberg-Shukron, A., Hershkovitz, Y., Zeligson, S., Lee, M.K., Samson, A.O., Parsons, S.M., King, M.C., Levy-Lahad, E., Walsh, T., 2017. Vesicular acetylcholine transporter defect underlies devastating congenital myasthenia syndrome. Neurology 88, 1021-1028. https://doi.org/10.1212/WNL.0000000000003720.

Aravamudan, B., Mantilla, C.B., Zhan, W.-Z., Sieck, G.C., 2006. Denervation effects on myonuclear domain size of rat diaphragm fibers. J. Appl. Physiol. 100.

Bauché, S., O'Regan, S., Azuma, Y., Laffargue, F., McMacken, G., Sternberg, D., Brochier, G., Buon, C., Bouzidi, N., Topf, A., Lacène, E., Remerand, G., Beaufrere, A.M., PebrelRichard, C., Thevenon, J., El Chehadeh-Djebbar, S., Faivre, L., Duffourd, Y., Ricci, F., Mongini, T., Fiorillo, C., Astrea, G., Burloiu, C.M.M., Butoianu, N., Sandu, C., Servais, L., Bonne, G., Nelson, I., Desguerre, I., Nougues, M.C., Bœuf, B., Romero, N., Laporte, J., Boland, A., Lechner, D., Deleuze, J.F., Fontaine, B., Strochlic, L., Lochmuller, H., Eymard, B., Mayer, M., Nicole, S., 2016. Impaired presynaptic high-affinity choline transporter causes a congenital myasthenic syndrome with episodic apnea. Am. J. Hum. Genet. 99, 753-761. https://doi.org/10.1016/j.ajhg.2016.06.033.

Biral, D., Scarpini, E., Angelini, C., Salviati, G., Margreth, A., 1989. Myosin heavy chain composition of muscle fibers in spinal muscular atrophy. Muscle Nerve 12, 43-51. https://doi.org/10.1002/mus.880120109.

Bloemberg, D., Quadrilatero, J., 2012. Rapid determination of myosin heavy chain expression in rat, mouse, and human skeletal muscle using multicolor immunofluorescence analysis. e35273. PLoS One 7https://doi.org/10.1371/journal.pone. 0035273. rPONE-D-11-20138 [pii].

Bodine, S.C., Baehr, L.M., 2014. Skeletal muscle atrophy and the E3 ubiquitin ligases MuRF1 and MAFbx/atrogin-1. Am. J. Physiol. Metab 307, E469-E484. https://doi. org/10.1152/ajpendo.00204.2014.

Bonaldo, P., Sandri, M., 2013. Cellular and molecular mechanisms of muscle atrophy. Dis. Model. Mech 6, 25-39. https://doi.org/10.1242/dmm.010389. 
Bowman, W.C., Prior, C., Marshall, I.G., 1990. Presynaptic receptors in the neuromuscular junction. Ann. N. Y. Acad. Sci. 604, 69-81.

Brandon, E.P., Lin, W., D'Amour, K. a, Pizzo, D.P., Dominguez, B., Sugiura, Y., Thode, S., Ko, C.-P., Thal, L.J., Gage, F.H., Lee, K.-F., 2003. Aberrant patterning of neuromuscular synapses in choline acetyltransferase-deficient mice. J. Neurosci. 23, 539-549 doi:23/2/539 [pii].

Brooke, M.H., Kaiser, K.K., 1970. Muscle fiber types: how many and what kind? Arch. Neurol. 23, 369-379. https://doi.org/10.1001/archneur.1970.00480280083010.

Byring, R.F., Pihko, H., Tsujino, a, Shen, X.-M., Gustafsson, B., Hackman, P., Ohno, K. Engel, a G., Udd, B., 2002. Congenital myasthenic syndrome associated with episodic apnea and sudden infant death. Neuromuscul. Disord. 12, 548-553. https://doi.org/ 10.1016/S0960-8966(01)00336-4.

Chakkalakal, J.V., Nishimune, H., Ruas, J.L., Spiegelman, B.M., Sanes, J.R., 2010. Retrograde influence of muscle fibers on their innervation revealed by a novel marker for slow motoneurons. Development 137, 3489-3499. https://doi.org/10.1242/dev. 053348.

Darabid, H., Perez-Gonzalez, A.P., Robitaille, R., 2014. Neuromuscular synaptogenesis: coordinating partners with multiple functions. Nat. Rev. Neurosci. 1-16. https://doi org/10.1038/nrn3821.

de Castro, B.M., De Jaeger, X., Martins-Silva, C., Lima, R.D.F., Amaral, E., Menezes, C., Lima, P., Neves, C.M.L., Pires, R.G., Gould, T.W., Welch, I., Kushmerick, C., Guatimosim, C., Izquierdo, I., Cammarota, M., Rylett, R.J., Gomez, M.V., Caron, M.G., Oppenheim, R.W., Prado, M.A.M., Prado, V.F., 2009. The vesicular acetylcholine transporter is required for neuromuscular development and function. Mol. Cell Biol. 29, 5238-5250. https://doi.org/10.1128/MCB.00245-09.

Di Giulio, I., Maganaris, C.N., Baltzopoulos, V., Loram, I.D., 2009. The proprioceptive and agonist roles of gastrocnemius, soleus and tibialis anterior muscles in maintaining human upright posture. J. Physiol. 587, 2399-2416. https://doi.org/10.1113/ jphysiol.2009.168690.

Engel, A.G., Selcen, D., Shen, X.-M., Milone, M., Harper, C.M., 2016. Loss of MUNC13-1 function causes microcephaly, cortical hyperexcitability, and fatal myasthenia. Neurol. Genet. 2, e105. https://doi.org/10.1212/NXG.0000000000000105.

Ferreira-Vieira, T.H., Bastos, C.P., Pereira, G.S., Moreira, F.A., Massensini, A.R., 2014. A role for the endocannabinoid system in exercise-induced spatial memory enhancement in mice. Hippocampus 24, 79-88. https://doi.org/10.1002/hipo.22206.

Ganguly, D.K., Das, M., 1979. Effects of oxotremorine demonstrate presynaptic muscarinic and dopaminergic receptors on motor nerve terminals. Nature 278, 645-646. https://doi.org/10.1038/278645a0.

Gautam, M., DeChiara, T.M., Glass, D.J., Yancopoulos, G.D., Sanes, J.R., 1999. Distinct phenotypes of mutant mice lacking agrin, MuSK, or rapsyn. Dev. Brain Res. 114, 171-178. https://doi.org/10.1016/S0165-3806(99)00013-9.

Hanzlíková, V., Macková, E.V., Hník, P., 1975. Satellite cells of the rat soleus muscle in the process of compensatory hypertrophy combined with denervation. Cell Tissue Res. 160, 411-421. https://doi.org/10.1007/BF00222049.

Harandi, V.M., Lindquist, S., Kolan, S.S., Brännström, T., Liu, J.X., 2014. Analysis of neurotrophic factors in limb and extraocular muscles of mouse model of amyotrophic lateral sclerosis. PLoS One 9, e109833. https://doi.org/10.1371/journal.pone. 0109833.

Herrmann, D.N., Horvath, R., Sowden, J.E., Gonzales, M., Sanchez-Mejias, A., Guan, Z., Whittaker, R.G., Almodovar, J.L., Lane, M., Bansagi, B., Pyle, A., Boczonadi, V., Lochmuller, H., Griffin, H., Chinnery, P.F., Lloyd, T.E., Troy Littleton, J., Zuchner, S., 2014. Synaptotagmin 2 mutations cause an autosomal-dominant form of lamberteaton myasthenic syndrome and nonprogressive motor neuropathy. Am. J. Hum. Genet. 95, 332-339. https://doi.org/10.1016/j.ajhg.2014.08.007.

Holloszy, J., Chen, M., Cartee, G., Young, J., 1991. Skeletal muscle atrophy in old rats: differential changes in the three fiber types. Mech. Ageing Dev. 60, 199-213. https:// doi.org/10.1016/0047-6374(91)90131-I.

Hyatt, J.-P.K., Roy, R.R., Baldwin, K.M., Edgerton, V.R., 2003. Nerve activity-independent regulation of skeletal muscle atrophy: role of MyoD and myogenin in satellite cells and myonuclei. Am. J. Physiol. Cell Physiol. 285, C1161-C1173. https://doi.org/10. 1152/ajpcell.00128.2003.

Ingram, D.K., London, E.D., Reynolds, M.A., Waller, S.B., Goodrick, C.L., 1981. Differential effects of age on motor performance in two mouse strains. Neurobiol. Aging 2, 221-227. https://doi.org/10.1016/0197-4580(81)90025-7.

Katz, B., Miledi, R., 1964. The development of acetylcholine sensitivity in nerve-free segments of skeletal muscle. J. Physiol. 170, 389-396. https://doi.org/10.1113/ jphysiol.1964.sp007339.

Kljakic, O., Janickova, H., Prado, V.F., Prado, M.A.M., 2017. Cholinergic/glutamatergic co-transmission in striatal cholinergic interneurons: new mechanisms regulating striatal computation. J. Neurochem. https://doi.org/10.1111/jnc.14003.

Langley, J.N., 1907. On the contraction of muscle, chiefly in relation to the presence of "receptive" substances: Part I. J. Physiol. 36, 347-384. https://doi.org/10.1113/ jphysiol.1907.sp001236.

Lara, A., Damasceno, D.D., Pires, R., Gros, R., Gomes, E.R., Gavioli, M., Lima, R.F., Guimarães, D., Lima, P., Bueno, C.R., Vasconcelos, A., Roman-Campos, D., Menezes, C.A.S., Sirvente, R.A., Salemi, V.M., Mady, C., Caron, M.G., Ferreira, A.J., Brum, P.C, Resende, R.R., Cruz, J.S., Gomez, M.V., Prado, V.F., de Almeida, A.P., Prado, M.A.M., Guatimosim, S., 2010. Dysautonomia due to reduced cholinergic neurotransmission causes cardiac remodeling and heart failure. Mol. Cell Biol. 30, 1746-1756. https:// doi.org/10.1128/MCB.00996-09.

Larsson, L., Ansved, T., 1995. Effects of ageing on the motor unit. Prog. Neurobiol. https://doi.org/10.1016/0301-0082(95)98601-Z.

Larsson, L., Biral, D., Campione, M., Schiaffino, S., 1993. An age?related type IIB to IIX myosin heavy chain switching in rat skeletal muscle. Acta Physiol. Scand. 147, 227-234. https://doi.org/10.1111/j.1748-1716.1993.tb09493.x.

Larsson, L., Müller, U., Li, X., Schiaffino, S., 1995. Thyroid hormone regulation of myosin heavy chain isoform composition in young and old rats, with special reference to IIX myosin. Acta Physiol. Scand. 153, 109-116. https://doi.org/10.1111/j.1748-1716. 1995.tb09841.x.

Leite, H.R., Oliveira-Lima, O.C., de Pereira, L. de M., Oliveira, V.E. de M., Prado, V.F., Prado, M.A.M., Pereira, G.S., Massensini, A.R., 2016. Vesicular acetylcholine transporter knock down-mice are more susceptible to inflammation, c-Fos expression and sickness behavior induced by lipopolysaccharide. Brain Behav. Immun. 57, 282-292. https://doi.org/10.1016/j.bbi.2016.05.005.

Lima, R., de, F., Prado, V.F., Prado, M.A.M., Kushmerick, C., 2010. Quantal release of acetylcholine in mice with reduced levels of the vesicular acetylcholine transporter. J. Neurochem. 113, 943-951. https://doi.org/10.1111/j.1471-4159.2010.06657.x.

Miljkovic, N., Lim, J.Y., Miljkovic, I., Frontera, W.R., 2015. Aging of skeletal muscle fibers. Ann. Rehabil. Med. 39 (2), 155-162. https://doi.org/10.5535/arm.2015.39.2. 155.

Mimaki, M., Wang, X., McKenzie, M., Thorburn, D.R., Ryan, M.T., 2012. Understanding mitochondrial complex I assembly in health and disease. Biochim. Biophys. Acta Bioenerg. 1817, 851-862. https://doi.org/10.1016/j.bbabio.2011.08.010.

Minderis, P., Kilikevicius, A., Baltusnikas, J., Alhindi, Y., Venckunas, T., Bunger, L., Lionikas, A., Ratkevicius, A., 2016. Myostatin dysfunction is associated with reduction in overload induced hypertrophy of soleus muscle in mice. Scand. J. Med. Sci. Sports 26, 894-901. https://doi.org/10.1111/sms.12532.

Miner, J., Noakes, P., Son, Y., 1998. Development of the neuromuscular junction : genetic analysis in mice. J. Physiol. 167-172.

Miranda, D.R., Wong, M., Romer, S.H., McKee, C., Garza-Vasquez, G., Medina, A.C., Bahn, V., Steele, A.D., Talmadge, R.J., Voss, A.A., 2017. Progressive $\mathrm{Cl}$ - channel defects reveal disrupted skeletal muscle maturation in R6/2 Huntington's mice. J. Gen. Physiol. 149, 55-74. https://doi.org/10.1085/jgp.201611603.

Misgeld, T., Burgess, R.W., Lewis, R.M., Cunningham, J.M., Lichtman, J.W., Sanes, J.R., 2002. Roles of neurotransmitter in synapse formation. Neuron 36, 635-648. https:// doi.org/10.1016/S0896-6273(02)01020-6.

Moresi, V., Williams, A.H., Meadows, E., Flynn, J.M., Potthoff, M.J., McAnally, J. Shelton, J.M., Backs, J., Klein, W.H., Richardson, J.A., Bassel-Duby, R., Olson, E.N., 2010. Myogenin and class II HDACs control neurogenic muscle atrophy by inducing E3 ubiquitin ligases. Cell 143, 35-45. https://doi.org/10.1016/j.cell.2010.09.004.

O'Grady, G.L., Verschuuren, C., Yuen, M., Webster, R., Menezes, M., Fock, J.M., Pride, N., Best, H.A., Benavides Damm, T., Turner, C., Lek, M., Engel, A.G., North, K.N., Clarke, N.F., Macarthur, D.G., Kamsteeg, E.J., Cooper, S.T., 2016. Variants in SLC18A3, vesicular acetylcholine transporter, cause congenital myasthenic syndrome. Neurology 87, 1442-1448. https://doi.org/10.1212/WNL.0000000000003179.

O'Neill, G.N., 2006. Inherited disorders of the neuromuscular junction. Int. Anesthesiol. Clin. 44 (2), 91-106. https://doi.org/10.1097/00004311-200604420-00006.

Ohno, K., Rahman, M.A., Nazim, M., Nasrin, F., Lin, Y., Takeda, J., ichi, Masuda, A., 2017. Splicing regulation and dysregulation of cholinergic genes expressed at the neuromuscular junction. J. Neurochem. https://doi.org/10.1111/jnc.13954.

Ohno, K., Tsujino, A., Brengman, J.M., Harper, C.M., Bajzer, Z., Udd, B., Beyring, R., Robb, S., Kirkham, F.J., Engel, A.G., 2001. Choline acetyltransferase mutations cause myasthenic syndrome associated with episodic apnea in humans. Proc. Natl. Acad. Sci. Unit. States Am. 98, 2017-2022. https://doi.org/10.1073/pnas.98.4.2017.

Parsons, S.M., 2000. Transport mechanisms in acetylcholine and monoamine storage. Faseb. J. 14, 2423-2434. https://doi.org/10.1096/fj.00-0203rev.

Pcr, R.T., Pfaffl, M.W., 2001. A new mathematical model for relative quantification in. Nucleic Acids Res. 29, 16-21. https://doi.org/10.1093/nar/29.9.e45.

Petrosino, J.M., Heiss, V.J., Maurya, S.K., Kalyanasundaram, A., Periasamy, M., Lafountain, R.A., Wilson, J.M., Simonetti, O.P., Ziouzenkova, O., 2016. Graded maximal exercise testing to assess mouse cardio-metabolic phenotypes. PLoS One 11. https://doi.org/10.1371/journal.pone.0148010.

Prado, V.F., Martins-Silva, C., de Castro, B.M., Lima, R.F., Barros, D.M., Amaral, E., Ramsey, A.J., Sotnikova, T.D., Ramirez, M.R., Kim, H.G., Rossato, J.I., Koenen, J., Quan, H., Cota, V.R., Moraes, M.F.D., Gomez, M.V., Guatimosim, C., Wetsel, W.C., Kushmerick, C., Pereira, G.S., Gainetdinov, R.R., Izquierdo, I., Caron, M.G., Prado, M.A.M., 2006. Mice deficient for the vesicular acetylcholine transporter are myasthenic and have deficits in object and social recognition. Neuron 51, 601-612. https://doi.org/10.1016/j.neuron.2006.08.005.

Prado, V.F., Roy, A., Kolisnyk, B., Gros, R., Prado, M.a M., 2013. Regulation of cholinergic activity by the vesicular acetylcholine transporter. Biochem. J. 450, 265-274. https://doi.org/10.1042/BJ20121662.

Rodrigues, H.A., Fonseca, M., de, C., Camargo, W.L., Lima, P.M.A., Martinelli, P.M., Naves, L.A., Prado, V.F., Prado, M.A.M., Guatimosim, C., 2013. Reduced expression of the vesicular acetylcholine transporter and neurotransmitter content affects synaptic vesicle distribution and shape in mouse neuromuscular junction. PLoS One 8, e78342. https://doi.org/10.1371/journal.pone.0078342.

Sacheck, J.M., Ohtsuka, A., McLary, S.C., Goldberg, A.L., 2004. IGF-I stimulates muscle growth by suppressing protein breakdown and expression of atrophy-related ubiquitin ligases, atrogin-1 and MuRF1. Am. J. Physiol. Endocrinol. Metab. 287, E591-E601. https://doi.org/10.1152/ajpendo.00073.2004.

Sango, K., McDonald, M.P., Crawley, J.N., Mack, M.L., Tifft, C.J., Skop, E., Starr, C.M., Hoffmann, A., Sandhoff, K., Suzuki, K., Proia, R.L., 1996. Mice lacking both subunits of lysosomal beta-hexosaminidase display gangliosidosis and mucopolysaccharidosis. Nat. Genet. 14, 348-352. https://doi.org/10.1038/ng1196-348.

Santafé, M.M., Salon, I., Garcia, N., Lanuza, M.A., Uchitel, O.D., Tomàs, J., 2003. Modulation of ACh release by presynaptic muscarinic autoreceptors in the neuromuscular junction of the newborn and adult rat. Eur. J. Neurosci. 17, 119-127.

Schiaffino, S., Gorza, L., Sartore, S., Leopoldo, S., Simonetta, A., Vianello, M., Gundersen, K., Lomo, T., 1989. Three myosin heavy chain isoforms in type 2 skeletal muscle fibres. J. Muscle Res. Cell Motil. 10, 197-205. https://doi.org/10.1007/BF01739810. Schiaffino, S., Reggiani, C., 2011. Fiber types in mammalian skeletal muscles. Physiol. 
Rev. 91, 1447-1531. https://doi.org/10.1152/physrev.00031.2010.

Schwartz, M., Sternberg, D., Whalen, S., Afenjar, A., Isapof, A., Chabrol, B., Portnoï, M.-F., Heide, S., Keren, B., Chantot-Bastaraud, S., Siffroi, J.-P., 2018. How chromosomal deletions can unmask recessive mutations? Deletions in 10q11.2 associated with CHAT or SLC18A3 mutations lead to congenital myasthenic syndrome. Am. J. Med. Genet. 176, 151-155. https://doi.org/10.1002/ajmg.a.38515.

Shen, X.-M., Scola, R.H., Lorenzoni, P.J., Audia, C., Kay, S.K., Werneck, L.C., Brengman, J., Selcen, D., Engel, A.G., 2017. Novel synaptobrevin-1 mutation causes fatal congenital myasthenic syndrome. Ann. Clin. Transl. Neurol 4, 130-138. https://doi.org/ 10.1002/acn3.387.

Shen, X.-M., Selcen, D., Brengman, J., Engel, A.G., 2014. Mutant SNAP25B causes myasthenia, cortical hyperexcitability, ataxia, and intellectual disability. Neurology 83, 2247-2255. https://doi.org/10.1212/WNL.0000000000001079.

Silva, J.F., Correa, I.C., Diniz, T.F., Lima, P.M., Santos, R.L., Cortes, S.F., Coimbra, C.C., Lemos, V.S., 2016. Obesity, inflammation, and exercise training: relative contribution of inos and enos in the modulation of vascular function in the mouse aorta. Front. Physiol. 7. https://doi.org/10.3389/fphys.2016.00386.

Sousa, N., Almeida, O.F.X., Wotjak, C.T., 2006. A hitchhiker's guide to behavioral analysis in laboratory rodents. Gene Brain Behav. 5 (Suppl 2), 5-24. https://doi.org/10.1111/ j.1601-183X.2006.00228.x.

Speakman, J.R., 2013. Measuring energy metabolism in the mouse - theoretical, practical, and analytical considerations. Front. Physiol. 4, 34. https://doi.org/10.3389/fphys. 2013.00034.

Starke, K., Göthert, M., Kilbinger, H., 1989. Modulation of neurotransmitter release by presynaptic autoreceptors. Physiol. Rev. 69, 864-989.

Thompson, L.V., 1994. Effects of age and training on skeletal muscle physiology and performance. Phys. Ther. 74, 71-81.
Valdez, G., Tapia, J.C., Lichtman, J.W., Fox, M.A., Sanes, J.R., 2012. Shared resistance to aging and ALS in neuromuscular junctions of specific muscles. PLoS One 7 (4), e34640. https://doi.org/10.1371/journal.pone.0034640.

Vianna, M.R., Alonso, M., Viola, H., Quevedo, J., de Paris, F., Furman, M., de Stein, M.L., Medina, J.H., Izquierdo, I., 2000. Role of hippocampal signaling pathways in longterm memory formation of a nonassociative learning task in the rat. Learn. Mem. 7, 333-340. https://doi.org/10.1101/lm.34600.

Vizi, E.S., Somogyi, G.T., 1989. Prejunctional modulation of acetylcholine release from the skeletal neuromuscular junction: link between positive (nicotinic) - and negative (muscarinic)-feedback modulation. Br. J. Pharmacol. 97, 65-70. https://doi.org/10. 1111/j.1476-5381.1989.tb11924.x.

Wang, Y., Pessin, J.E., 2013. Mechanisms for fiber-type specificity of skeletal muscle atrophy. Curr. Opin. Clin. Nutr. Metab. Care 16, 243-250. https://doi.org/10.1097/ MCO.0b013e328360272d.

Wessler, I., 1989. Control of transmitter release from the motor nerve by presynaptic nicotinic and muscarinic autoreceptors. Trends Pharmacol. Sci. 10, 110-114. https:// doi.org/10.1016/0165-6147(89)90208-3.

Yoon, J.C., Puigserver, P., Chen, G., Donovan, J., Wu, Z., Rhee, J., Adelmant, G., Stafford, J., Kahn, C.R., Granner, D.K., Newgard, C.B., Spiegelman, B.M., Mun, E., DeFronzo, R., Finlayson, J., Kahn, C.R., Mandarino, L.J., Lander, E.S., Hirschhorn, J.N., Altshuler, D., Groop, L.C., 2001. Mechanisms controlling mitochondrial biogenesis and respiration through the thermogenic coactivator PGC-1. Nature 413, 131-138. https://doi.org/10.1038/35093050.

Zhan, W.Z., Sieck, G.C., 1992. Adaptations of diaphragm and medial gastrocnemius muscles to inactivity. J. Appl. Physiol. 72 (4), 1445-1453. https://doi.org/10.1152/ jappl.1992.72.4.1445. 